\title{
The effectiveness of patient-centred medical home-based models of care versus standard primary care in chronic disease management: a systematic review and meta-analysis of randomised and non-randomised controlled trials
}

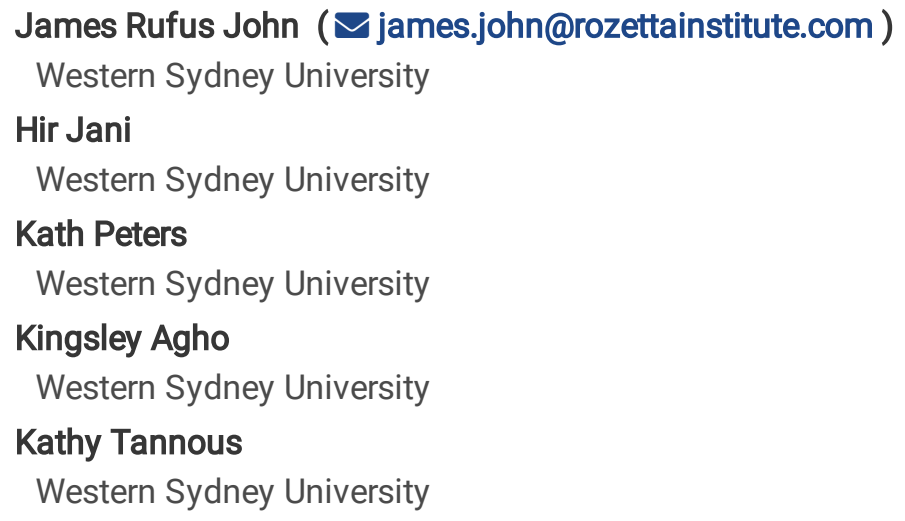

Research article

Keywords: Patient-centred medical home, enhanced primary care, chronic disease management, collaborative care, meta-analysis Posted Date: June 19th, 2020

DOI: https://doi.org/10.21203/rs.3.rs-35151/v1

License: (c) (1) This work is licensed under a Creative Commons Attribution 4.0 International License. Read Full License 


\section{Abstract \\ Background}

Patient-centred care by a coordinated primary care team may be more effective than standard care in chronic disease management. We synthesised evidence to determine whether patient-centred medical home (PCMH)-based care models are more effective than standard general practitioner (GP) care in improving clinical, hospital, and economic outcomes.

\section{Methods}

MEDLINE, CINAHL, Embase, Cochrane Library, and Scopus were searched to identify randomised (RCTs) and non-randomised controlled trials that evaluated two or more principles of PCMH among primary care patients with chronic diseases. Study selection, data extraction, quality assessment using Joanna Briggs Institute (JBI) appraisal tools, and grading of evidence using Grading of Recommendations, Assessment, Development and Evaluation (GRADE) approach were conducted independently. A quantitative synthesis, where possible, was pooled using random effects models and the effect size estimates of standardised mean differences (SMDs) and odds ratios (ORs) with 95\% confidence intervals were reported.

\section{Results}

Of the 13820 citations, we identified 78 eligible RCTs and 7 quasi trials which included 60617 patients. The findings suggested that PCMH-based care was associated with significant improvements in depression episodes (SMD $-0.24 ; 95 \% \mathrm{Cl}-0.35,-0.14$ ) and increased odds of remission (OR 1.79; $95 \% \mathrm{Cl} 1.46,2.21)$. There were significant improvements in the health-related quality of life (SMD 0.10; 95\% Cl 0.04, 0.15); self-management outcomes (SMD 0.24; 95\% Cl 0.03, 0.44) and hospital admissions (OR $0.83 ; 95 \% \mathrm{Cl} 0.70,0.98)$. In terms of clinical outcomes, with exception to total cholesterol, PCMH-based care led to significant improvements in blood pressure, glycated haemoglobin, and low-density lipoprotein cholesterol outcomes. The incremental cost of PCMH care was identified to be small and significantly higher than standard care (SMD $0.17 ; 95 \% \mathrm{Cl} 0.08,0.26)$. The quality of individual studies ranged from 'fair' to 'good' by meeting at least $60 \%$ of items on the quality appraisal checklist. Additionally, moderate to high heterogeneity across studies in outcomes resulted in downgrading the included studies as moderate or low grade of evidence.

\section{Conclusion}

PCMH-based care has been found to be superior to standard GP care in chronic disease management. Results of the review have important implications that may inform patient, practice, and policy-level changes.

\section{Background}

Chronic diseases have contributed to increased mortality and morbidity worldwide with the disease burden accelerating across both developed and developing nations [1, 2]. The Global Burden of Diseases (GBD) Study in 2017 reported that chronic diseases accounted for $41 \%$ of increased disability and $73 \%$ of all deaths $[1,2]$. Moreover, with increasing life expectancy and ageing population, the global prevalence of multiple chronic conditions or multimorbidity is also on the rise, further exacerbating complications in quality and delivery of care $[3,4]$. As a result, patients with one or more chronic diseases often experience poor mental and physical functioning with increased psychological distress affecting their overall health-related quality of life (HRQoL) $[5,6]$. Besides negative health outcomes, chronic diseases also contribute to significant economic ramifications to both patients and health care system in the form of increased health care utilisation and costs of care $[7,8]$.

The long-term nature of chronic diseases and complexities of care require health care systems, worldwide, to revisit guidelines on effective chronic disease management [7]. The health and economic repercussions of chronic diseases are partly connected to the fragmented design and delivery of health care systems to focus on 'single disease framework' as opposed to a 'whole-person 
approach' [9]. However, there has been an increasing advocacy towards shift from a reactive health care system to one that is proactive, enabling an integrated systems approach towards chronic disease management [10]. In view of this, the World Health Organisation (WHO) and other leading organisations have acknowledged the importance of primary care as an ideal setting to facilitate patient-centred care, which could result in better patient outcomes [11,12]. There is a large body of evidence suggesting that coordinated team-based approaches in primary care are effective in chronic disease management $[13,14]$.

The patient-centred medical home (PCMH) model is one of the chronic care models (CCM) that has reportedly shown to provide a multidimensional solution to effectively managing chronic illness and multimorbidity in primary care [15]. This enhanced primary care model typically consists of a general practitioner (GP)-led care, as part of a multidisciplinary team (MDT) that aims to provide patient-centred care that is also comprehensive and coordinated, with emphasis on self-management and patient education [12]. There is a growing body of literature, particularly in United States and several parts of United Kingdom and other European countries, reporting the effectiveness of PCMH care models in improving clinical [16, 17], HRQoL [18, 19], hospital [20, 21], and economic outcomes [22] compared to standard GP care.

A comprehensive systematic review and meta-analysis of PCMH care published in 2013 [23] reported improvements in patient experiences and some reduction in health utilisation among patients with multimorbidity. However, the effect of PCMH models on patients with single-disease care management was not reviewed. Whilst the review focuses on clinical quality and processes of care, there was insufficient evidence to estimate clinical outcomes and quality of life. In addition, the review also included patients from non-primary care settings such as tertiary care hospitals, thereby limiting understanding of the true effectiveness of $\mathrm{PCMH}$ model in primary care settings. The current review was warranted as there has been increased advocacy for PCMH-based care models resulting in a number of new studies evaluating PCMH models being published since 2013 [18-21].

A systematic review and meta-analysis was conducted to assess the effectiveness of PCMH-based models of care when compared to standard GP care in improving clinical, hospital, and economic outcomes of primary care patients with one or more chronic diseases. The findings of this review may help inform guidelines and practices.

\section{Methods}

This review conformed to the Preferred Reporting Items for Systematic Reviews and Meta-Analyses (PRISMA) guidelines [24]. The systematic review protocol (CRD42018085378), registered in the International Prospective Register of Systematic Reviews (PROSPERO) database, has been published elsewhere [25].

\section{Search strategy}

We conducted literature searches on electronic databases like MEDLINE, CINAHL, Embase, Cochrane library, and Scopus from inception until March 31, 2020. The search strategy and syntaxes were developed in collaboration with an experienced university librarian. The syntax explored a broad range of terms used in definitions of PCMH, collaborative care, chronic care models, RCTs, and Quasi trials (full electronic search strings are listed in Appendix 1). We supplemented electronic searches by hand-searching bibliographies of several key systematic reviews [23, 26-28] and retrieved studies to identify any relevant articles missed by the search strategy. Endnote (Version X9, Thompson Reuters, New York) software was used for reference management.

\section{Eligibility criteria and study selection}

A detailed inclusion and exclusion criteria for this review is reported elsewhere [25]. A summary of Population, Interventions, Comparators, Outcomes, and Study designs (PICOS) framework is presented in Fig. 1. Two reviewers (JRJ and KP) independently screened the titles and abstracts of all articles for eligibility. Following the title and abstract screening, a full text screening was conducted on articles which passed the title and abstract screening by two reviewers (JRJ and HJ) independently. Discrepancies were resolved and clarified through discussion.

\section{Data extraction}

Data extraction of included articles was carried out independently by two reviewers (JRJ and HJ) using Excel spreadsheet (Microsoft Excel, Microsoft Corporation). Data extracted from included articles included key characteristics: first author and 
publication year; country of origin; sample size, age and gender distribution; chronic disease profile; baseline characteristics reported as mean (SD) or proportions; PCMH components implemented; duration of follow-up; and outcomes. Whilst data extraction was performed using a customised spreadsheet, the Centre for Reviews and Dissemination's (CRD) guidance for undertaking reviews in health care was followed [29]. Authors of studies with missing data were contacted by email up to two times, however, no response was received.

\section{Quality assessment and Risk of bias}

Two reviewers (JRJ and $\mathrm{HJ}$ ) independently evaluated the methodological validity of included articles using relevant Joanna Briggs Institute (JBI) critical appraisal checklists (RCTs, quasi trials, and economic evaluations) [30, 31]. Quality of studies were rated as good ( $\geq 8)$, fair (6-7), or poor ( $\leq 5)$ based on the summary scores. We also used Risk of Bias In Non-randomised Studies of Interventions (ROBINS-I) tool to supplement JBI appraisal for non-randomised trials [32]. Additionally, the quality of evidence across included studies reporting similar outcomes was determined by applying the Grading of Recommendations Assessment, Development and Evaluation (GRADE) criteria [33].

\section{Outcomes}

Outcomes identified from the studies include changes in mean differences or proportion of patients achieving recommended levels in:

1) Biomedical outcomes - blood pressure (BP); glycated haemoglobin (HbA1c); low density lipoprotein cholesterol (LDL-C); high density lipoprotein cholesterol (HDL-C); and serum total cholesterol.

2) Self-reported health assessments (using validated questionnaires) - depression; HRQoL (overall, mental and physical functioning components); and self-management.

3) Health utilisation outcomes - hospital admissions; emergency department visits; and medications use.

4) Economic outcomes - total health care costs and incremental cost-effectiveness.

\section{Data analysis}

Data of included studies were pooled together using the inverse-variance method of random-effects meta-analysis [34]. Standardised mean differences (SMD) for continuous data and odds ratios (ORs) for dichotomous data, with $95 \%$ confidence intervals $(\mathrm{Cl})$, were calculated and graphically presented as forest plots. Statistical heterogeneity was calculated using $\mathrm{I}^{2}$ and Cochran's Q statistics. Subgroup analyses were considered for outcomes with substantial heterogeneity $\left(\mathrm{I}^{2} \geq 85 \%\right)$. Publication bias for outcomes with at least 6 studies was assessed using funnel plots and Egger's test of asymmetry [35]. All analyses were conducted using RevMan version 5.3 and $R$ version 4.0 software.

\section{Results}

Literature search

The electronic database search resulted in 13820 citations and an additional 16 citations from hand searching key systematic reviews. After exclusion of duplicate records, 6416 articles were screened by titles and abstracts with 201 articles determined to be eligible for full-text assessment. Of these, 85 studies met the eligibility criteria and were included in our systematic review. Flowchart of the selection process from initial identification to inclusion is shown in Fig. 2. Main reasons for exclusion included patients treated in non-primary care settings, not meeting minimum PCMH components or focused on intervention other than PCMH model, lack of control group, and other reasons (list of excluded articles; see Appendix 2).

\section{Descriptive data synthesis}

The characteristics of included studies are presented in Appendix 3-4. Of the 85 studies included in the review, 78 studies were RCTs $[13,14,16,18-20,22,36-106]$ and 7 studies were of non-RCTs, including quasi trials $[17,21,107,108]$ or cohort studies

Page $4 / 27$ 
with a control group [109-111]. The 85 studies enrolled a total of 60617 patients with sample sizes ranging from 40 to 8366 . Whilst 79 studies had sufficient data for quantitative data synthesis, 6 studies $[81,85,95,97,103,107]$ did not have usable data and therefore, the findings were narratively summarised.

The common inclusion criteria for all 85 studies was primary care patients with diagnosis of one or more chronic conditions, whereas the predominant reason for exclusion was patients with cognitive impairment and terminal illness. More than half the studies (52\%) were conducted in the United States. The mean age of patients ranged between 30 and 83 years. In terms of gender distribution, most studies had a slight female predilection except for studies conducted in Veterans Affairs (VA) primary care settings $[16,50,52,53,56]$. The duration of follow-up varied from 3 to 48 months.

\section{Quality assessment and risk of bias}

Quality assessment and risk of bias for individual studies are reported in Appendix 5-8. The overall quality of studies ranged from 'fair' to 'good' by meeting at least $60 \%$ of items on the checklist. Two studies $[62,104]$ were rated as poor due to general lack of information on randomisation, unclear methodology, and clarity of results. Given the nature of PCMH-based intervention, most trials employed a cluster randomisation method where a group of patients were seen by the same GP or same general practice providing PCMH care. Thereby, blinding of patients or GPs was not applicable and, as a result, items related to blinding were not necessarily graded down. However, only 32 studies reported blinding of outcome assessment whilst other studies were graded down in quality. The quality of evidence across included studies assessed using GRADE approach is presented in Tables 1-2. 
Table 1

GRADE assessment of randomised controlled trials reporting effectiveness of PCMH vs standard GP care on outcomes of interest

\begin{tabular}{|c|c|c|c|c|c|c|c|}
\hline Outcome & $\begin{array}{l}\text { No of } \\
\text { studies }\end{array}$ & $\begin{array}{l}\text { Risk of } \\
\text { bias }\end{array}$ & Inconsistency & Indirectness & Imprecision & $\begin{array}{l}\text { Publication } \\
\text { bias }\end{array}$ & $\begin{array}{l}\text { GRADE } \\
\text { quality of } \\
\text { evidence }\end{array}$ \\
\hline Depression & 30 & Serious & Serious & Not serious & Not serious & Undetected & Moderate \\
\hline Quality of Life & 19 & Serious & Not serious & Not serious & Not serious & Undetected & Moderate $^{\ddagger}$ \\
\hline Blood pressure & 12 & Serious & Not serious & Not serious & Not serious & Undetected & Moderate ${ }^{\ddagger}$ \\
\hline Glycated Hemoglobin & 8 & Serious & Serious & Not serious & Not serious & Undetected & Low $^{ \pm 9}$ \\
\hline LDL Cholesterol & 3 & Serious & Serious & Not serious & Not serious & Undetected & Low $^{ \pm 9}$ \\
\hline Total Cholesterol & 1 & Serious & - & Not serious & Not serious & Undetected & $\operatorname{Low}^{\ddagger \wedge}$ \\
\hline Hospital admissions & 3 & Serious & Not serious & Not serious & Not serious & Undetected & Moderate ${ }^{\ddagger}$ \\
\hline $\begin{array}{l}\text { Self-management } \\
\text { (PACIC scores) }\end{array}$ & 3 & Serious & Serious & Not serious & Not serious & Undetected & $\operatorname{Low}^{ \pm 9}$ \\
\hline Cost-effectiveness & 18 & Serious & Serious & Not serious & Not serious & Undetected & $\operatorname{Low}^{ \pm 9}$ \\
\hline \multicolumn{8}{|c|}{$\begin{array}{l}\text { PHigh quality: Further research is very unlikely to change our confidence in the estimate of effect; Moderate quality: Further } \\
\text { research is likely to have an important impact on our confidence in the estimate of effect and may change the estimate; Low } \\
\text { quality: Further research is very likely to have an important impact on our confidence in the estimate of effect and is likely to } \\
\text { change the estimate; Very low quality: We are very uncertain about the estimate. }\end{array}$} \\
\hline \multicolumn{8}{|c|}{$\begin{array}{l}{ }^{\ddagger} \text { Most studies did not blind participants or personnel as it was not practical. Therefore, we did not downgrade for these } \\
\text { risks/uncertainties. However studies not reporting blinding of outcome assessment were downgraded in quality. }\end{array}$} \\
\hline \multicolumn{8}{|c|}{ §Most studies did not mention allocation concealment strategies. } \\
\hline \multicolumn{8}{|c|}{${ }^{9}$ Significant level of heterogeneity within results ( $\mathrm{I}^{2}$ between $\left.80-90 \%\right)$} \\
\hline
\end{tabular}


Table 2

GRADE assessment of non-randomised studies reporting effectiveness of PCMH vs standard GP care on outcomes of interest

\begin{tabular}{|c|c|c|c|c|c|c|c|}
\hline Outcome & $\begin{array}{l}\text { No of } \\
\text { studies }\end{array}$ & $\begin{array}{l}\text { Risk of } \\
\text { bias }\end{array}$ & Inconsistency & Indirectness & Imprecision & $\begin{array}{l}\text { Publication } \\
\text { bias }\end{array}$ & Certainty \\
\hline Depression & 1 & Serious & - & Not serious & Not serious & Undetected & $\operatorname{Low}^{\dagger \neq \wedge}$ \\
\hline Quality of Life & 2 & Serious & Not serious & Not serious & Serious & Undetected & Moderate $e^{\dagger \uparrow}$ \\
\hline Blood pressure & 1 & Serious & - & Not serious & Not serious & Undetected & $\operatorname{Low}^{\dagger \neq \wedge}$ \\
\hline $\begin{array}{l}\text { Glycated } \\
\text { Hemoglobin }\end{array}$ & 1 & Serious & - & Not serious & Not serious & Undetected & Low $^{\dagger \ddagger^{\dagger}}$ \\
\hline LDL Cholesterol & 1 & Serious & - & Not serious & Serious & Undetected & $\operatorname{Low}^{\dagger \neq \wedge}$ \\
\hline HDL Cholesterol & 1 & Serious & - & Not serious & Not serious & Undetected & $\operatorname{Low}^{\dagger \ddagger \wedge}$ \\
\hline Total Cholesterol & 1 & Serious & - & Not serious & Not serious & Undetected & $\operatorname{Low}^{\dagger \ddagger \wedge}$ \\
\hline $\begin{array}{l}\text { Hospital } \\
\text { admissions }\end{array}$ & 2 & Serious & Not serious & Not serious & Not serious & Undetected & Moderate $^{\dagger \neq}$ \\
\hline $\begin{array}{l}\text { Cost- } \\
\text { effectiveness }\end{array}$ & 1 & Serious & - & Not serious & Not serious & Undetected & $\operatorname{Low}^{\dagger \ddagger \wedge}$ \\
\hline \multicolumn{8}{|c|}{${ }^{\dagger}$ Because of the nature of the quasi-experimental designs risk of bias is unavoidable } \\
\hline \multicolumn{8}{|c|}{$\begin{array}{l}\text { ‡Most did not blind participants or personnel as it was not practical. Therefore, we did not downgrade for these } \\
\text { risks/uncertainties. However studies not reporting blinding of outcome assessment were downgraded in quality. }\end{array}$} \\
\hline
\end{tabular}

\section{Depression outcomes}

Meta-analysis of thirty-one studies $[13,14,18,19,36,38,40,42,43,46,50,51,53,55,57,63,67,68,70,76,78,83,84,86-88,91$, $93,100,102,109]$ of patients with minor or major depression episodes after PCMH-based care reported significant improvement in depression scores compared to patients with standard primary care. With the exceptions of three studies [46, 91, 102], twentytwo studies reporting changes in mean differences (continuous data) of depression scores showed significant reduction with a pooled SMD of -0.24 (95\% Cl -0.35, -0.14; p-value < 0.001) (Fig. 3).

Six studies reported that PCMH care was associated with significantly increased odds of remission of depression with pooled OR 1.79 (95\% Cl 1.46, 2.21; p-value < 0.001) (Fig. 3). Additionally, one other study [85] reported significant improvements among patients with anxiety and mood disorders with an effect size of $0.30(95 \% \mathrm{Cl} 0.05,0.55 ; \mathrm{p}$-value $=0.02)$ compared to standard care. Given most studies consistently reported improvements, the GRADE of evidence was classified as moderate quality (Tables 1 and 2).

\section{Quality of life outcomes}

Twenty-two studies $[18,19,21,22,41,46,49-51,53,59,68,72,76,86,89,91,100,102,105,106,108]$ evaluated the effectiveness of PCMH-based care on HRQoL (overall, physical component and mental component). Patients enrolled in $\mathrm{PMCH}-$ based care reported small but significant improvements in HRQoL compared to standard care with a pooled SMD of $0.10(95 \% \mathrm{Cl}$ $0.04,0.15$; p-value < 0.001) (Fig. 4). Additionally, one other study [85] reported significant improvements with an effect size of 0.38 $(95 \% \mathrm{Cl} 0.13,0.63 ; \mathrm{p}$-value $=0.003)$. Moderate heterogeneity was observed among included studies $\left(\mathrm{I}^{2}=57 \%\right)$, but test for subgroup differences were not significant. The GRADE of evidence was classified as moderate quality (Tables 1 and 2).

\section{Blood pressure outcomes}


Thirteen studies $[16,17,39,42,45,61,64,68,71,82,90,94,96]$ reported on the effect of PCMH care on blood pressure outcomes. Six studies reported that PCMH care was associated with significantly increased odds of BP control with pooled OR $2.03(95 \% \mathrm{Cl}$ 1.56, 2.65; p-value < 0.001) (Fig. 5). Seven studies reported significant improvements in systolic blood pressure (SBP), in favour of PCMH care, with pooled estimates of SMD $-0.15(95 \% \mathrm{Cl}-0.29,-0.01 ; \mathrm{p}$-value $=0.03)$. Similar reduction was observed across five studies reporting on diastolic blood pressure (DBP), but the pooled estimate of SMD $-0.12(95 \% \mathrm{Cl}-0.27,0.02 ; \mathrm{p}$-value $=0.09)$ failed to meet significance (Fig. 5). The GRADE of evidence was classified as moderate quality (Tables 1 and 2).

\section{Glycated haemoglobin outcomes}

Ten studies $[16,17,39,43,64,68,71,77,82,96]$ reported on the effect of PCMH care on HbA1c outcomes. Three studies reported that PCMH care was associated with increased odds of glycaemic control with pooled OR $2.37(95 \% \mathrm{Cl} 0.86,6.51 ; \mathrm{p}$-value = 0.100). However, the pooled estimate was not statistically significant (Fig. 6). The substantial heterogeneity of $87 \%$ in the three studies reporting ORs was due to a shorter follow-up duration of 3 months reported by Bogner et al [43] compared to the other two studies which had follow-up duration of 12 to 13 months. Seven studies reported significant improvements in $\mathrm{HbA1c}$, in favour of PCMH care with pooled estimates of SMD $-0.26(95 \% \mathrm{Cl}-0.43,-0.08$; p-value $=0.004)$ (Fig. 6). Given the substantial amount of heterogeneity, the GRADE of evidence was classified as low quality (Tables 1 and 2).

\section{Cholesterol outcomes}

For LDL-cholesterol outcomes, five studies $[17,64,68,71,96]$ reported significant improvements in favour of PCMH care with pooled SMD of $-0.16(95 \% \mathrm{Cl}-0.33,-0.00 ; p$-value $=0.05)$ compared to standard GP care. Test for subgroup difference between follow-up and change scores showed no statistical significance $\left(I^{2}=16.8 \%\right.$, $p$-value $\left.=0.27\right)($ Fig. $7 \mathrm{~A})$. For total cholesterol outcomes, two studies $[17,82]$ reported a non-significant increase in total cholesterol with a pooled SMD of $0.07(95 \% \mathrm{Cl}-0.08$, 0.23 ; p-value $=0.34)($ Fig. 7B). The GRADE of evidence of both LDL and total cholesterol outcomes were classified as low quality given the limited number of studies (Tables 1 and 2).

\section{Hospital admissions}

Five studies $[20,21,48,54,111]$ reported that PCMH care was associated with significant reduction in hospital admissions compared to standard care with pooled OR $0.83(95 \% \mathrm{Cl} 0.70,0.98 ; \mathrm{p}$-value $=0.02)$ (Fig. 8). Additionally, one study [110] reported a reduction in mean hospital admission rates related to diabetic complications 12 months after PCMH based care compared to standard care. Nonetheless, the change in mean difference failed to meet statistical significance. The GRADE of evidence was classified as moderate quality (Tables 1 and 2).

\section{Self-management outcomes}

Three studies $[14,72,89]$ reported significant improvements in self-management scores in favour of PCMH care compared to standard care with pooled estimates of SMD 0.24 (95\% Cl 0.03, 0.44; p-value < 0.001$)$ (Fig. 9). Given the substantial amount of heterogeneity $\left(I^{2}=83 \%\right)$, the GRADE of evidence was classified as low quality (Tables 1 and 2 ).

\section{Economic outcomes}

A total of 18 studies $[13,22,37,44,46,52,58-60,65,66,69,73,79,80,92,98,108]$ reported cost-effectiveness of PCMH-based models of care compared to standard care. To avoid bias in analysis, all currencies were converted to US Dollars at the time of the respective trials and cost effectiveness was measured in terms of incremental cost of intervention. The incremental cost of PCMH care was small but significantly higher than standard care with a pooled estimate of $0.17(95 \% \mathrm{Cl} 0.08,0.26$; $\mathrm{p}$-value < 0.001) (Fig. 10). The substantial heterogeneity of $81 \%$ was due to higher costs of intervention reported by Bosanquet et al [46]. The GRADE of evidence was classified as low quality (Tables 1 and 2).

A summary of results from meta-analyses (where possible) and individual studies from randomised and non-randomised controlled trials are presented in Table 3. 
Table 3

Summary of findings from meta-analyses (where possible) or individual studies from randomised and non-randomised controlled trials

\begin{tabular}{|c|c|c|c|c|c|c|c|c|c|}
\hline Outcome & $\begin{array}{l}\text { No of } \\
\text { studies }\end{array}$ & $\begin{array}{l}\text { No of } \\
\text { participants }\end{array}$ & $\begin{array}{l}\text { Effect } \\
\text { size } \\
(95 \% \\
\text { Cl) }\end{array}$ & $\begin{array}{l}\mathrm{p}- \\
\text { value }\end{array}$ & $\begin{array}{l}\text { Q } \\
\text { statistic }\end{array}$ & $\left.\right|^{2}$ & $\begin{array}{l}\text { Egger's } \\
\text { test } \\
\text { p- } \\
\text { value }^{\ddagger}\end{array}$ & Citations & Figure \\
\hline \multicolumn{10}{|c|}{ Randomised controlled trials } \\
\hline \multirow[t]{3}{*}{ Depression } & 24 & 7255 & \multirow{2}{*}{$\begin{array}{l}\text { SMD - } \\
0.24 \\
(-0.35 \\
-0.14)\end{array}$} & \multirow{3}{*}{$\begin{array}{l}< \\
0.001 \\
< \\
0.001\end{array}$} & 78.3 & $76 \%$ & 0.275 & \multirow{3}{*}{$\begin{array}{l}{[13,14,18,19,36,38} \\
40,42,43,46,50,51 \\
53,55,57,63,67,68 \\
70,76,78,83,84,86- \\
88,91,93,100,102 \\
109]\end{array}$} & \multirow[t]{3}{*}{3} \\
\hline & 6 & 1520 & & & 3.58 & $0 \%$ & 0.608 & & \\
\hline & & & $\begin{array}{l}\text { OR } \\
1.79 \\
(1.46 \\
2.21)\end{array}$ & & & & & & \\
\hline $\begin{array}{l}\text { Quality of } \\
\text { Life }\end{array}$ & 22 & 12370 & $\begin{array}{l}\text { SMD } \\
0.12 \\
(0.09 \\
0.15)\end{array}$ & $\begin{array}{l}< \\
0.001\end{array}$ & 57.38 & $51 \%$ & 0.556 & $\begin{array}{l}{[18,19,21,22,41,46,} \\
49-51,53,59,68,72, \\
76,86,89,91,100 \\
102,105,106,108]\end{array}$ & 4 \\
\hline \multirow{6}{*}{$\begin{array}{l}\begin{array}{l}\text { Blood } \\
\text { pressure }\end{array} \\
\text { BP control } \\
\text { Systolic BP } \\
\text { Diastolic BP }\end{array}$} & 6 & 1202 & \multirow{3}{*}{$\begin{array}{l}\text { OR } \\
2.03 \\
(1.56 \\
2.65)\end{array}$} & \multirow{3}{*}{$\begin{array}{l}< \\
0.001 \\
0.09\end{array}$} & 5.30 & $6 \%$ & 0.347 & \multirow{6}{*}{$\begin{array}{l}{[16,39,42,45,61,64} \\
68,71,82,90,94,96]\end{array}$} & \multirow[t]{6}{*}{5} \\
\hline & 6 & 1947 & & & 8.97 & $44 \%$ & 0.737 & & \\
\hline & \multirow{4}{*}{5} & \multirow{4}{*}{1836} & & & 7.82 & $49 \%$ & 0.260 & & \\
\hline & & & $\begin{array}{l}\text { SMD - } \\
0.08\end{array}$ & 0.10 & & & & & \\
\hline & & & $\begin{array}{l}(-0.17 \\
0.01)\end{array}$ & & & & & & \\
\hline & & & $\begin{array}{l}\text { SMD - } \\
0.12 \\
(-0.27 \\
0.02)\end{array}$ & & & & & & \\
\hline \multirow{2}{*}{$\begin{array}{l}\text { Glycated } \\
\text { haemoglobin }\end{array}$} & 3 & 726 & \multirow{2}{*}{$\begin{array}{l}2.37 \\
(0.86 \\
6.51)\end{array}$} & 0.001 & 15.00 & $87 \%$ & NA & \multirow{4}{*}{$\begin{array}{l}{[16,39,43,64,68,71} \\
77,82,96]\end{array}$} & \multirow[t]{4}{*}{6} \\
\hline & 6 & 2044 & & $<001$ & 27.75 & $82 \%$ & 0.405 & & \\
\hline control & & & \multirow{2}{*}{$\begin{array}{l}\text { SMD - } \\
0.21 \\
(-0.30 \\
-0.12)\end{array}$} & & & & & & \\
\hline$H b A 1 c$ & & & & & & & & & \\
\hline $\begin{array}{l}\text { LDL } \\
\text { Cholesterol }\end{array}$ & 4 & 1086 & $\begin{array}{l}\text { SMD - } \\
0.25 \\
(-0.37 \\
-0.13)\end{array}$ & $<.001$ & 1.64 & $0 \%$ & NA & {$[64,68,71,96]$} & $7 A$ \\
\hline $\begin{array}{l}\text { Total } \\
\text { Cholesterol }\end{array}$ & 1 & 888 & $\begin{array}{l}\text { SMD } \\
0.00 \\
(-0.13 \\
0.13)\end{array}$ & 1.00 & NA & NA & NA & [82] & 7B \\
\hline $\begin{array}{l}\text { Hospital } \\
\text { admissions }\end{array}$ & 3 & 4770 & $\begin{array}{l}\text { OR } \\
0.90 \\
(0.80 \\
1.03)\end{array}$ & 0.12 & 0.67 & $0 \%$ & NA & {$[20,48,54]$} & 8 \\
\hline
\end{tabular}

NA - not applicable

‡Egger's test was conducted only for outcomes with at least 6 studies. 


\begin{tabular}{|c|c|c|c|c|c|c|c|c|c|}
\hline Outcome & $\begin{array}{l}\text { No of } \\
\text { studies }\end{array}$ & $\begin{array}{l}\text { No of } \\
\text { participants }\end{array}$ & $\begin{array}{l}\text { Effect } \\
\text { size } \\
(95 \% \\
\text { Cl) }\end{array}$ & $\begin{array}{l}\mathrm{p}- \\
\text { value }\end{array}$ & $\begin{array}{l}\mathrm{Q} \\
\text { statistic }\end{array}$ & $\mathrm{I}^{2}$ & $\begin{array}{l}\text { Egger's } \\
\text { test } \\
\text { p- } \\
\text { value }^{\ddagger}\end{array}$ & Citations & Figure \\
\hline $\begin{array}{l}\text { Self- } \\
\text { management } \\
\text { (PACIC } \\
\text { scores) }\end{array}$ & 3 & 2440 & $\begin{array}{l}\text { SMD } \\
0.24 \\
(0.03 \\
0.44)\end{array}$ & 0.02 & 11.48 & $83 \%$ & NA & {$[14,72,89]$} & 9 \\
\hline $\begin{array}{l}\text { Cost- } \\
\text { effectiveness }\end{array}$ & 17 & 12612 & $\begin{array}{l}\text { SMD } \\
0.17 \\
(0.07 \\
0.26)\end{array}$ & 0.001 & 87.84 & $82 \%$ & 0.206 & $\begin{array}{l}{[13,22,37,44,46,52,} \\
58-60,65,66,69,73, \\
79,80,92,98]\end{array}$ & 10 \\
\hline \multicolumn{10}{|c|}{ Non-randomised trials } \\
\hline Depression & 1 & 314 & $\begin{array}{l}\text { SMD - } \\
0.22 \\
(-0.45 \\
0.01)\end{array}$ & 0.06 & NA & NA & NA & [109] & 3 \\
\hline $\begin{array}{l}\text { Quality of } \\
\text { Life }\end{array}$ & 2 & 833 & $\begin{array}{l}\text { SMD - } \\
0.08 \\
(-0.21 \\
0.06)\end{array}$ & 0.28 & 0.94 & $0 \%$ & NA & {$[22,108]$} & 4 \\
\hline $\begin{array}{l}\text { Blood } \\
\text { pressure } \\
\text { Systolic BP }\end{array}$ & 1 & 727 & $\begin{array}{l}\text { SMD - } \\
0.30 \\
(-0.45 \\
-0.16)\end{array}$ & $\begin{array}{l}<.001 \\
0.001\end{array}$ & NA & NA & NA & [17] & 5 \\
\hline $\begin{array}{l}\text { Glycated } \\
\text { haemoglobin }\end{array}$ & 1 & 727 & $\begin{array}{l}\text { SMD - } \\
0.20 \\
(-0.35 \\
-0.06)\end{array}$ & 0.006 & NA & NA & NA & {$[17]$} & 6 \\
\hline $\begin{array}{l}\text { LDL } \\
\text { Cholesterol }\end{array}$ & 1 & 727 & $\begin{array}{l}\text { SMD } \\
0.06 \\
(-0.09 \\
0.20)\end{array}$ & 0.43 & NA & NA & NA & [17] & 7 \\
\hline $\begin{array}{l}\text { HDL } \\
\text { Cholesterol }\end{array}$ & 1 & 727 & $\begin{array}{l}\text { SMD } \\
0.15 \\
(0.00 \\
0.29)\end{array}$ & 0.05 & NA & NA & NA & {$[17]$} & - \\
\hline $\begin{array}{l}\text { Total } \\
\text { Cholesterol }\end{array}$ & 1 & 727 & $\begin{array}{l}\text { SMD } \\
0.16 \\
(0.01 \\
0.30)\end{array}$ & 0.04 & NA & NA & NA & [17] & 8 \\
\hline $\begin{array}{l}\text { Hospital } \\
\text { admissions }\end{array}$ & 2 & 912 & $\begin{array}{l}\text { OR } \\
0.63 \\
(0.48 \\
0.83)\end{array}$ & 0.001 & 0.02 & $0 \%$ & NA & {$[21,111]$} & 9 \\
\hline $\begin{array}{l}\text { Cost- } \\
\text { effectiveness }\end{array}$ & 1 & 358 & $\begin{array}{l}\text { SMD } \\
0.19 \\
(-0.01 \\
0.40)\end{array}$ & 0.07 & NA & NA & NA & [108] & 10 \\
\hline
\end{tabular}

NA - not applicable

${ }^{\ddagger}$ Egger's test was conducted only for outcomes with at least 6 studies. 
Six or more articles with similar outcomes were inspected for publication bias visually by using funnel plots and statistically by determining the significance from Egger's test of asymmetry. Visual inspection of included studies reporting similar outcomes did not indicate any obvious sign of asymmetry (Figs. 11 and 12). Consistent with visual findings, no evidence of publication bias was detected with Egger's test, as all outcomes had $p>0.05$, showing evidence of funnel plot symmetry (Table 3 ).

\section{Discussion}

\section{Summary of findings}

This systematic review comprehensively summarised current evidence on the effectiveness of PCMH-based models on chronic disease management among primary care patients. Compared to standard GP care, PCMH-based care led to significant improvements in depression episodes, quality of life, HbA1c, LDL cholesterol, hospital admissions, and self-management outcomes. Whilst PCMH care was significantly associated with increased odds of blood pressure control, reductions in both pooled estimates of SBP and DBP were not statistically significant. In contrast, the findings suggest that PCMH-based interventions have higher costs and was not cost-effective when compared to standard care. Additionally, the narrative synthesis of studies also corroborated with pooled estimates of the meta-analyses.

\section{Consistency with other systematic reviews}

The most commonly reported PCMH principles in the included studies were patient engagement through education and selfmanagement, and care coordination in addition to team-based care. Findings of this review, underscoring these PMCH elements in primary care, are consistent with previous systematic reviews reporting quality of care and overall patient experiences [26, 112]. In terms of study outcomes, depression and HRQoL were frequently reported outcomes in the included studies. Systematic reviews focussing on depression outcomes as a result of collaborative care reported similar improvements, which were consistent with our pooled estimates of SMDs and ORs $[113,114]$. Similarly, our review showed small but significant improvements in the self-reported HRQoL and self-management scores, which is consistent with previous reviews $[115,116]$. Variabilities in the duration of intervention and baseline severity of chronic illness may explain smaller pooled estimates of HRQoL outcome.

Changes in clinical outcomes are common measures employed in evaluating the effectiveness of chronic disease management interventions. With the exception of total cholesterol outcomes, findings of our studies were consistent with previous reviews $[117,118]$, showing improvements in clinical outcomes in favour of PCMH-based care compared to standard care. In terms of cost-effectiveness of PCMH-based models, some meta-analytic reviews on economic evaluations showed that PCMH care was associated with decreases in total costs compared to standard care $[119,120]$. However, our review supports evidence from prior reviews $[115,121]$, suggesting that PCMH-based care was not associated with improvement in cost outcomes compared to standard care. This discordance could be due to the variability in the initial and sustained amount of costs incurred as a result of additional staffing and other infrastructure as well as the sample of patients and their comorbidity profile in the included trials [121].

\section{Strengths and limitations}

Quality assessment for risk of bias was assessed within and across studies of similar outcomes. As aforementioned, blinding of patients and GPs was not possible due to the nature of intervention and design of trials, as reported in other systematic reviews conducted in primary care settings $[114,122]$. A substantial amount of heterogeneity was observed for measures of depression, $\mathrm{HbA1c}$, and incremental cost of intervention, justifying the choice of random effects model. Higher heterogeneity is expected when pooling results of complex interventions, given the varying levels of intensity of different interventions and country's primary care setting [115]. Nonetheless, pooled estimates must be interpreted with caution because of unexplained variation observed in outcomes with higher heterogeneity. The review did not consider unpublished data or non-English language studies given the exhaustive number of citations identified. This may have had potential impact on effect size estimates.

Whilst previous reviews and meta-analyses on collaborative care for either single specific disease or multimorbidity have been studied, this review provides a comprehensive current evidence with quantitative synthesis on the effectiveness of PCMH-based

Page $11 / 27$ 
care models exclusively on primary care patients with one or more chronic diseases. Other strengths include a registered and published protocol, with a peer-reviewed search strategy, conducted on a wide range of electronic databases.

\section{Patient, provider, and policy-level implications and future directions}

Findings of our systematic review have important implications at patient, practice, and policy-level. The evidence may inform patients on the enhanced clinical outcomes and quality of life resulting from improved education and self-management support. The transformational changes at practice level may enable GPs to better target and deliver care according to the level and complexity of different patients [123]. Additionally, our study findings may also impact policy and implementation guidelines given the growing advocacy towards patient-centred care. Future research should focus on evaluating sustained benefits of PCMH-based care as well as supporting holistic experiences of patients receiving patient-centred care.

\section{Conclusion}

Current evidence suggests that PCMH-based care is superior to standard GP care in chronic disease management. Findings of our review showed significant improvements in depression, HRQoL, self-management, clinical, and health utilisation outcomes. Whilst studies included for pooled estimates showed consistent trend for several outcomes, high heterogeneity in some outcomes resulted in low to moderate grade of evidence, limiting firmer conclusion from the pooled evidence. Further research is needed to evaluate the long-term cost-effectiveness of PCMH-based care after the initial higher costs incurred for intervention, which may prove to be more cost-effective than standard care.

\section{Abbreviations}

BP: blood pressure; CCM:chronic care model; Cl:confidence interval; CINAHL:Cumulative Index to Nursing and Allied Health Literature; CRD:Centre for Reviews and Dissemination; DBP:Diastolic blood pressure; GBD:Global Burden of Diseases; GP:general practitioner; GRADE:Grading of Recommendations, Assessment, Development and Evaluation; HbA1c:glycated haemoglobin; HDL-C:high-density lipoprotein cholesterol; HRQoL:health-related quality of life; JBI:Joanna Briggs Institute; LDL-C:low-density lipoprotein cholesterol; MDT:multidisciplinary team; OR:odds ratio; PCMH:Patient-centred medical home; PICOS:Population, Interventions, Comparators, Outcomes, and Study designs; PRISMA:Preferred Reporting Items for Systematic Reviews and MetaAnalyses; PROSPERO:Prospective Register of Systematic Reviews; RCT:randomised controlled trial; SBP:systolic blood pressure; SD:standard deviation; SMD:standardised mean difference; VA:Veterans Affairs; WHO:World Health Organisation.

\section{Declarations}

\section{Ethics approval and consent to participate}

Not applicable.

\section{Consent for publication}

Not applicable.

\section{Availability of data and materials}

All data generated or analysed during this study are included in this article and its supplementary information files.

\section{Competing interests}

The authors declare that they have no competing interests.

\section{Funding}

JRJ's PhD scholarship was provided by Capital Markets Cooperative Research Centre (Now Rozetta Institute). The funders did not have any role in the design, methods, analysis, or preparation of this manuscript. 


\section{Author's contributions}

JRJ was involved in the conception, design, data screening, data extraction, quality assessment and grading, data analysis and interpretation and write up of the manuscript. HJ was involved in the data screening, quality assessment and grading, and review of the manuscript. KP was involved in the data screening and review of the manuscript. KA was contributed to data analysis and review of the manuscript. WKT was involved in PhD supervision and review of the manuscript. All authors have approved the submitted version.

\section{Acknowledgements}

The authors would like to express their gratitude to Ms. Katrina Chaudhary (Librarian, School of Science and Health, Western Sydney University) and Ms. Lily Collison (Librarian, School of Medicine, Western Sydney University) for their help in developing search terms and guidance during the initial search process. We are also particularly grateful to Dr Evan Atlantis for his valuable expertise and feedback provided for this study.

\section{References}

1. Hay SI, Abajobir AA, Abate KH, Abbafati C, Abbas KM, Abd-Allah F, et al. Global, regional, and national disability-adjusted lifeyears (DALYs) for 333 diseases and injuries and healthy life expectancy (HALE) for 195 countries and territories, 1990-2016: a systematic analysis for the Global Burden of Disease Study 2016. Lancet. 2017;390:1260-344.

2. Naghavi M, Abajobir AA, Abbafati C, Abbas KM, Abd-Allah F, Abera SF, et al. Global, regional, and national age-sex specific mortality for 264 causes of death, 1980-2016: a systematic analysis for the Global Burden of Disease Study 2016. Lancet. 2017;390:1151-210.

3. van Oostrom SH, Gijsen R, Stirbu I, Korevaar JC, Schellevis FG, Picavet HSJ, et al. Time trends in prevalence of chronic diseases and multimorbidity not only due to aging: data from general practices and health surveys. PloS one. 2016;11.

4. Afshar S, Roderick PJ, Kowal P, Dimitrov BD, Hill AG. Multimorbidity and the inequalities of global ageing: a cross-sectional study of 28 countries using the World Health Surveys. BMC Public Health. 2015;15:776.

5. Fortin M, Lapointe L, Hudon C, Vanasse A, Ntetu AL, Maltais D. Multimorbidity and quality of life in primary care: a systematic review. Health Qual Life Outcomes. 2004;2:51.

6. Megari K. Quality of life in chronic disease patients. Health Psychol Res. 2013;1(3): e27.

7. McPhail SM. Multimorbidity in chronic disease: impact on health care resources and costs. Risk Manag Healthc Policy. 2016;9:143.

8. Vogeli C, Shields AE, Lee TA, Gibson TB, Marder WD, Weiss KB, et al. Multiple chronic conditions: prevalence, health consequences, and implications for quality, care management, and costs. J Gen Intern Med. 2007;22:391-5.

9. Barnett K, Mercer SW, Norbury M, Watt G, Wyke S, Guthrie B. Epidemiology of multimorbidity and implications for health care, research, and medical education: a cross-sectional study. Lancet. 2012;380:37-43.

10. Coleman K, Austin BT, Brach C, Wagner EH. Evidence on the chronic care model in the new millennium. Health Aff. 2009;28:75-85.

11. World Health Organisation. Multimorbidity: Technical Series on Safer Primary Care. Geneva. 2016. https://apps.who.int/iris/bitstream/handle/10665/252275/9789241511650-eng.pdf?sequence=1 Accessed 13 April 2020.

12. Australian Medical Association. AMA Position Statement on the Medical Home - 2015. https://ama.com.au/positionstatement/ama-position-statement-medical-home Accessed 12 April 2020.

13. Camacho EM, Davies LM, Hann M, Small N, Bower P, Chew-Graham C, et al. Long-term clinical and cost-effectiveness of collaborative care (versus usual care) for people with mental-physical multimorbidity: cluster-randomised trial. $\mathrm{Br} \mathrm{J}$ Psychiatry. 2018:1-8.

14. Coventry P, Lovell K, Dickens C, Bower P, Chew-Graham C, McElvenny D, et al. Integrated primary care for patients with mental and physical multimorbidity: cluster randomised controlled trial of collaborative care for patients with depression comorbid with diabetes or cardiovascular disease. BMJ. 2015;350:h638. 
15. Maeng DD, Graf TR, Davis DE, Tomcavage J, Bloom Jr FJ. Can a patient-centered medical home lead to better patient outcomes? The quality implications of Geisinger's ProvenHealth Navigator. Am J Med Qual. 2012;27:210-6.

16. Edelman D, Fredrickson SK, Melnyk SD, Coffman CJ, Jeffreys AS, Datta S, et al. Medical clinics versus usual care for patients with both diabetes and hypertension: a randomized trial. Ann Intern Med. 2010;152:689-96.

17. Bray P, Cummings DM, Morrissey S, Thompson D, Holbert D, Wilson K, et al. Improved outcomes in diabetes care for rural African Americans. Ann Fam Med. 2013;11:145-50.

18. Aragonès E, Caballero A, Piñol J-L, López-Cortacans G. Persistence in the long term of the effects of a collaborative care programme for depression in primary care. J Affect Disord. 2014;166:36-40.

19. Muntingh A, Van Der Feltz-cornelis C, Van Marwijk H, Spinhoven P, Assendelft W, De Waal M, et al. Effectiveness of collaborative stepped care for anxiety disorders in primary care: a pragmatic cluster randomised controlled trial. Psychother Psychosom. 2014;83:37-44.

20. Campins L, Serra-Prat M, Gózalo I, López D, Palomera E, Agustí C, et al. Randomized controlled trial of an intervention to improve drug appropriateness in community-dwelling polymedicated elderly people. Fam Pract. 2017;34:36-42.

21. Ruikes FG, Zuidema SU, Akkermans RP, Assendelft WJ, Schers HJ, Koopmans RT. Multicomponent program to reduce functional decline in frail elderly people: a cluster controlled trial. J Am Board Fam Med. 2016;29:209-17.

22. Konnopka A, König H-H, Kaufmann C, Egger N, Wild B, Szecsenyi J, et al. Cost-utility of a specific collaborative group intervention for patients with functional somatic syndromes. J Psychosom Res. 2016;90:43-50.

23. Jackson GL, Powers BJ, Chatterjee R, Bettger JP, Kemper AR, Hasselblad V, et al. The patient-centered medical Home: A Systematic review. Ann Intern Med. 2013;158:169-78.

24. Moher D, Shamseer L, Clarke M, Ghersi D, Liberati A, Petticrew M, et al. Preferred reporting items for systematic review and meta-analysis protocols (PRISMA-P) 2015 statement. Sys Rev. 2015;4:1.

25. John JR, Ghassempour S, Girosi F, Atlantis E. The effectiveness of patient-centred medical home model versus standard primary care in chronic disease management: protocol for a systematic review and meta-analysis of randomised and nonrandomised controlled trials. Sys Rev. 2018;7:1-6.

26. Rathert C, Wyrwich MD, Boren SA. Patient-centered care and outcomes: a systematic review of the literature. Med Care Res Rev. 2013;70:351-79.

27. Hoff T, Weller W, DePuccio M. The patient-centered medical home: a review of recent research. Med Care Res Rev. 2012;69:619-44.

28. Bernstein KM, Manning DA, Julian RM. Multidisciplinary teams and obesity: role of the modern patient-centered medical home. Prim Care. 2016;43:53-9.

29. Tacconelli E. Systematic reviews: CRD's guidance for undertaking reviews in health care. Lancet Infect Dis. 2010;10:226.

30. Aromataris E, Munn Z. Joanna Briggs Institute reviewer's manual. The Joanna Briggs Institute. 2017;299.

31. Gomersall JS, Jadotte YT, Xue Y, Lockwood S, Riddle D, Preda A. Conducting systematic reviews of economic evaluations. Int J Evid Based Healthc. 2015;13:170-8.

32. Sterne JA, Hernán MA, Reeves BC, Savović J, Berkman ND, Viswanathan M, et al. ROBINS-l: a tool for assessing risk of bias in non-randomised studies of interventions. BMJ. 2016;355:i4919.

33. Guyatt GH, Oxman AD, Vist GE, Kunz R, Falck-Ytter Y, Alonso-Coello P, et al. GRADE: an emerging consensus on rating quality of evidence and strength of recommendations. BMJ. 2008;336:924-6.

34. Higgins JP, Thompson SG. Quantifying heterogeneity in a meta-analysis. Stat Med. 2002;21:1539-58.

35. Egger M, Smith GD, Schneider M, Minder C. Bias in meta-analysis detected by a simple, graphical test. BMJ. 1997;315:62934.

36. Alexopoulos GS, Reynolds CF, 3rd, Bruce ML, Katz IR, Raue PJ, Mulsant BH, et al. Reducing suicidal ideation and depression in older primary care patients: 24-month outcomes of the PROSPECT study. Am J Psychiatry. 2009;166:882-90.

37. Aragones E, Lopez-Cortacans G, Sanchez-Iriso E, Pinol JL, Caballero A, Salvador-Carulla L, et al. Cost-effectiveness analysis of a collaborative care programme for depression in primary care. J Affect Disord. 2014;159:85-93.

Page $14 / 27$ 
38. Aragones E, Rambla C, Lopez-Cortacans G, Tome-Pires C, Sanchez-Rodriguez E, Caballero A, et al. Effectiveness of a collaborative care intervention for managing major depression and chronic musculoskeletal pain in primary care: a clusterrandomised controlled trial. J Affect Disord. 2019;252:221-9.

39. Barceló A, Cafiero E, De Boer M, Mesa AE, Lopez MG, Jiménez RA, et al. Using collaborative learning to improve diabetes care and outcomes: The VIDA project. Prim Care Diabetes. 2010;4:145-53.

40. Björkelund C, Svenningsson I, Hange D, Udo C, Petersson EL, Ariai N, et al. Clinical effectiveness of care managers in collaborative care for patients with depression in Swedish primary health care: A pragmatic cluster randomized controlled trial. BMC Fam Pract. 2018;19.

41. Blom J, Elzen WD, Houwelingen AHV, Heijmans M, Stijnen T, Van Den Hout W, et al. Effectiveness and cost-effectiveness of a proactive, goal-oriented, integrated care model in general practice for older people. A cluster randomised controlled trial: Integrated systematic care for older people-the ISCOPE study. Age Ageing. 2016;45:30-41.

42. Bogner HR, de Vries HF, Bogner HR, de Vries HF. Integration of depression and hypertension treatment: a pilot, randomized controlled trial. Ann Fam Med. 2008;6:295-301.

43. Bogner HR, Morales KH, de Vries HF, Cappola AR, Bogner HR, Morales KH, et al. Integrated management of type 2 diabetes mellitus and depression treatment to improve medication adherence: a randomized controlled trial. Ann Fam Med. 2012;10:15-22.

44. Boland MRS, Kruis AL, Tsiachristas A, Assendelft WJJ, Gussekloo J, Blom CMG, et al. Cost-effectiveness of integrated COPD care: The RECODE cluster randomised trial. BMJ Open. 2015;5.

45. Borenstein JE, Graber G, Saltiel E, Wallace J, Ryu S, Jackson A, et al. Physician-pharmacist comanagement of hypertension: A randomized, comparative trial. Pharmacotherapy. 2003;23:209-16.

46. Bosanquet K, Adamson J, Atherton K, Bailey D, Baxter C, Beresford-Dent J, et al. CollAborative care for Screen-Positive EldeRs with major depression (CASPER plus): a multicentred randomised controlled trial of clinical effectiveness and costeffectiveness. Health Technol Assess. 2017;21:1-252.

47. Boult C, Reider L, Frey K, Left B, Boyd CM, Wolff JL, et al. Early Effects of "Guided Care" on the Quality of Health Care for Multimorbid Older Persons: A Cluster-Randomized Controlled Trial. J Gerontol A Biol Sci Med Sci. 2008;63:321-7.

48. Boult C, Reider L, Leff B, Frick KD, Boyd CM, Wolff JL, et al. The effect of guided care teams on the use of health services: results from a cluster-randomized controlled trial. Arch Intern Med. 2011;171:460-6.

49. Callahan CM, Kroenke K, Counsell SR, Hendrie HC, Perkins AJ, Katon W, et al. Treatment of depression improves physical functioning in older adults. J Am Geriatr Soc. 2005;53:367-73.

50. Chaney EF, Rubenstein LV, Liu C-F, Yano EM, Bolkan C, Lee M, et al. Implementing collaborative care for depression treatment in primary care: a cluster randomized evaluation of a quality improvement practice redesign. Implement Sci. 2011;6:121.

51. Cooper LA, Ghods Dinoso BK, Ford DE, Roter DL, Primm AB, Larson SM, et al. Comparative effectiveness of standard versus patient-centered collaborative care interventions for depression among African Americans in primary care settings: the BRIDGE Study. Health Serv Res. 2013;48:150-74.

52. Dickinson KC, Sharma R, Duckart JP, Corson K, Gerrity MS, Dobscha SK. VA healthcare costs of a collaborative intervention for chronic pain in primary care. Med Care. 2010;48:38-44.

53. Dobscha SK, Corson K, Perrin NA, Hanson GC, Leibowitz RQ, Doak MN, et al. Collaborative care for chronic pain in primary care: a cluster randomized trial. JAMA. 2009;301:1242-52.

54. Dorr DA, Wilcox AB, Brunker CP, Burdon RE, Donnelly SM. The effect of technology-supported, multidisease care management on the mortality and hospitalization of seniors. J Am Geriatr Soc. 2008;56:2195-202.

55. Engel CC, Jaycox LH, Freed MC, Bray RM, Brambilla D, Zatzick D, et al. Centrally assisted collaborative telecare for posttraumatic stress disorder and depression among military personnel attending primary care a randomized clinical trial. JAMA Intern Med. 2016;176:948-56.

56. Fihn SD, Bucher JB, McDonell M, Diehr P, Rumsfeld JS, Doak M, et al. Collaborative care intervention for stable ischemic heart disease. Arch Intern Med. 2011;171:1471-9. 
57. Gilbody S, Lewis H, Adamson J, Atherton K, Bailey D, Birtwistle J, et al. Effect of Collaborative Care vs Usual Care on Depressive Symptoms in Older Adults With Subthreshold Depression: the CASPER Randomized Clinical Trial. JAMA. 2017;317:728-37.

58. Goorden M, Huijbregts, K.M., van Marwijk, H.W., Beekman, A.T., van der Feltz-Cornelis, C.M. and Hakkaart-van Roijen, L. Costutility of collaborative care for major depressive disorder in primary care in the Netherlands. J Psychosom Res. 2015;79(4):316-323.

59. Green C, Richards DA, Hill JJ, Gask L, Lovell K, Chew-Graham C, et al. Cost-effectiveness of collaborative care for depression in UK primary care: economic evaluation of a randomised controlled trial (CADET). Plos one. 2014;9:e104225.

60. Grochtdreis T, Brettschneider C, Bjerregaard F, Bleich C, Boczor S, Harter M, et al. Cost-effectiveness analysis of collaborative treatment of late-life depression in primary care (GermanIMPACT). Eur Psychiatry. 2019;57:10-8.

61. Hirsch JD, Steers N, Adler DS, Kuo GM, Morello CM, Lang M, et al. A randomized controlled trial of primary care based pharmacist-physician collaborative medication therapy management for hypertension. J Gen Intern Med. 2013;28:S12.

62. Hsu C-C, Tai T-Y. Long-term glycemic control by a diabetes case-management program and the challenges of diabetes care in Taiwan. Diabetes Res Clin Pract. 2014;106 Suppl 2:S328-32.

63. Huijbregts KM, de Jong FJ, van Marwijk HW, Beekman AT, Adèr HJ, Hakkaart-van Roijen L, et al. A target-driven collaborative care model for Major Depressive Disorder is effective in primary care in the Netherlands. A randomized clinical trial from the depression initiative. J Affect Disord. 2013;146:328-37.

64. Ip EJ, Shah BM, Yu J, Chan J, Nguyen LT, Bhatt DC. Enhancing diabetes care by adding a pharmacist to the primary care team. Am J Health Syst Pharm. 2013;70:877-86.

65. Johnson JA, Lier DA, Soprovich A, Al Sayah F, Qiu W, Majumdar SR. Cost-effectiveness evaluation of collaborative care for diabetes and depression in primary care. Am J Prev Med. 2016;51:e13-e20.

66. Katon W, Russo J, Lin EHB, Schmittdiel J, Ciechanowski P, Ludman E, et al. Cost-effectiveness of a multicondition collaborative care intervention: a randomized controlled trial. Arch Gen Psychiatry. 2012;69:506-14.

67. Katon W, Von Korff M, Lin E, Simon G, Walker E, Unützer J, et al. Stepped collaborative care for primary care patients with persistent symptoms of depression: A randomized trial. Arch Gen Psychiatry. 1999;56:1109-15.

68. Katon WJ, Lin EH, Von Korff M, Ciechanowski P, Ludman EJ, Young B, et al. Collaborative care for patients with depression and chronic illnesses. N Engl J Med. 2010;363:2611-20.

69. Katon WJ, Schoenbaum M, Fan MY, Callahan CM, Williams J, Hunkeler E, et al. Cost-effectiveness of improving primary care treatment of late-life depression. Arch Gen Psychiatry. 2005;62:1313-20.

70. Katon WJ, Von Korff M, Lin EH, Simon G, Ludman E, Russo J, et al. The Pathways Study: a randomized trial of collaborative care in patients with diabetes and depression. Arch Gen Psychiatry. 2004;61:1042-9.

71. Krein SL, Klamerus ML, Vijan S, Lee JL, Fitzgerald JT, Pawlow A, et al. Case management for patients with poorly controlled diabetes: a randomized trial. Am J Med. 2004;116:732-9.

72. Kruis AL, Boland MR, Assendelft WJ, Gussekloo J, Tsiachristas A, Stijnen T, et al. Effectiveness of integrated disease management for primary care chronic obstructive pulmonary disease patients: results of cluster randomised trial. BMJ. 2014;349:g5392.

73. Leeuwen KM, Bosmans JE, Jansen APD, Hoogendijk EO, Muntinga ME, Hout HPJ, et al. Cost-Effectiveness of a Chronic Care Model for Frail Older Adults in Primary Care: Economic Evaluation Alongside a Stepped-Wedge Cluster-Randomized Trial. J Am Geriatr Soc. 2015;63:2494-504.

74. Lin EH, Tang L, Katon W, Hegel MT, Sullivan MD, Unützer J. Arthritis pain and disability: response to collaborative depression care. Gen Hosp Psychiatry. 2006;28:482-6.

75. Lin EH, Von Korff M, Ciechanowski P, Peterson D, Ludman EJ, Rutter CM, et al. Treatment adjustment and medication adherence for complex patients with diabetes, heart disease, and depression: a randomized controlled trial. Ann Fam Med. 2012;10:6-14. doi: 10.1370/afm.1343.

76. Lin EH, VonKorff M, Russo J, Katon W, Simon GE, Unützer J, et al. Can depression treatment in primary care reduce disability? A stepped care approach. Arch Fam Med. 2000;9:1052-8.

Page 16/27 
77. Maislos M, Weisman D. Multidisciplinary approach to patients with poorly controlled type 2 diabetes mellitus: a prospective, randomized study. Acta Diabetol. 2004;41:44-8.

78. Menchetti M, Sighinolfi C, Di Michele V, Peloso P, Nespeca C, Bandieri PV, et al. Effectiveness of collaborative care for depression in Italy. A randomized controlled trial. Gen Hosp Psychiatry. 2013;35:579-86.

79. Metzelthin SF, van Rossum E, Hendriks MR, De Witte LP, Hobma SO, Sipers W, et al. Reducing disability in communitydwelling frail older people: cost-effectiveness study alongside a cluster randomised controlled trial. Age Ageing. 2015;44:390-6.

80. Morgan RO, Bass DM, Judge KS, Liu CF, Wilson N, Snow AL, et al. A Break-Even Analysis for Dementia Care Collaboration: Partners in Dementia Care. J Gen Intern Med. 2015;30:804-9.

81. Pyne JM, Rost KM, Zhang M, Williams DK, Smith J, Fortney J. Cost-effectiveness of a primary care depression intervention. J Gen Intern Med. 2003;18:432-41.

82. Ramli AS, Selvarajah S, Daud MH, Haniff J, Abdul-Razak S, Tg-Abu-Bakar-Sidik TM, et al. Effectiveness of the EMPOWER-PAR Intervention in Improving Clinical Outcomes of Type 2 Diabetes Mellitus in Primary Care: a Pragmatic Cluster Randomised Controlled Trial. BMC Fam Pract. 2016;17:157.

83. Richards DA, Hill JJ, Gask, L., Lovell, K., Chew-Graham, C., Bower, P., Cape, J., Pilling, S., Araya, R., Kessler, D. and Bland, J.M. Clinical effectiveness of collaborative care for depression in UK primary care (CADET): cluster randomised controlled trial. BMJ. 2013;347:9-.

84. Richards DA, Lovell K, Gilbody S, Gask L, Torgerson D, Barkham M, et al. Collaborative care for depression in UK primary care: a randomized controlled trial. Psychol Med. 2008;38:279-87.

85. Rollman B, Belnap B, Mazumdar S, Abebe K, Karp J, Lenze E, et al. Telephone-Delivered Stepped Collaborative Care for Treating Anxiety in Primary Care: A Randomized Controlled Trial. J Gen Intern Med. 2017;32:245-55.

86. Rollman BL, Belnap BH, Mazumdar S, Houck PR, Zhu F, Gardner W, et al. A randomized trial to improve the quality of treatment for panic and generalized anxiety disorders in primary care. Arch Gen Psychiatry. 2005;62:1332-41.

87. Rollman BL, Herbeck Belnap B, Abebe KZ, Spring MB, Rotondi AJ, Rothenberger SD, et al. Effectiveness of Online Collaborative Care for Treating Mood and Anxiety Disorders in Primary Care: A Randomized Clinical Trial. JAMA Psychiatry. 2018;75:56-64.

88. Rost K, Nutting P, Smith J, Werner J, Duan N. Improving depression outcomes in community primary care practice: a randomized trial of the quEST intervention. Quality Enhancement by Strategic Teaming. J Gen Intern Med. 2001;16:143-9.

89. Salisbury C, Mei-See M, Bower P, Guthrie B, Chaplin K, Gaunt DM, et al. Management of multimorbidity using a patientcentred care model: a pragmatic cluster-randomised trial of the 3D approach. Lancet. 2018;392:41-50.

90. Scherpbier-de Haan ND, Vervoort GM, van Weel C, Braspenning JC, Mulder J, Wetzels JF, et al. Effect of shared care on blood pressure in patients with chronic kidney disease: a cluster randomised controlled trial. Br J Gen Pract. 2013;63:e798-806.

91. Schnurr PP, Friedman MJ, Oxman TE, Dietrich AJ, Smith MW, Shiner B, et al. RESPECT-PTSD: re-engineering systems for the primary care treatment of PTSD, a randomized controlled trial. J Gen Intern Med. 2013;28:32-40.

92. Simon GE, Katon WJ, VonKorff M, Unutzer J, Lin EH, Walker EA, et al. Cost-effectiveness of a collaborative care program for primary care patients with persistent depression. Am J Psychiatry. 2001;158:1638-44.

93. Simon GE, Ludman EJ, Tutty S, Operaskalski B, Von Korff M, Simon GE, et al. Telephone psychotherapy and telephone care management for primary care patients starting antidepressant treatment: a randomized controlled trial. JAMA. 2004;292:935-42.

94. Simpson SH, Majumdar SR, Tsuyuki RT, Lewanczuk RZ, Spooner R, Johnson JA. Impact of adding a pharmacist to primary care teams on blood pressure control in people with type 2 diabetes: a randomized controlled trial (ISRCTN97121854). Can J Diabetes. 2009; 33 (3):198-9.

95. Smith SM, Bury G, O'Leary M, Shannon W, Tynan A, Staines A, et al. The North Dublin randomized controlled trial of structural diabetes shared care. Fam Pract. 2004;21:39-45.

96. Tang PC, Overhage JM, Chan AS, Brown NL, Aghighi B, Entwistle MP, et al. Online disease management of diabetes: engaging and motivating patients online with enhanced resources-diabetes (EMPOWER-D), a randomized controlled trial. J 
Am Med Inform Assoc. 2013;20:526-34.

97. Taylor KI, Oberle KM, Crutcher RA, Norton PG. Promoting health in type 2 diabetes: Nurse-physician collaboration in primary care. Biol Res Nurs. 2005;6:207-15.

98. Thorn J, Man MS, Chaplin K, Bower P, Brookes S, Gaunt D, et al. Cost-effectiveness of a patient-centred approach to managing multimorbidity in primary care: a pragmatic cluster randomised controlled trial. BMJ Open. 2020;10.

99. Uijen AA, Bischoff EW, Schellevis FG, Bor HH, van den Bosch WJ, Schers HJ. Continuity in different care modes and its relationship to quality of life: a randomised controlled trial in patients with COPD. Br J Gen Pract. 2012;62:e422-8.

100. Unutzer J, Katon W, Callahan CM, Williams Jr JW, Hunkeler E, Harpole L, et al. Collaborative care management of late-life depression in the primary care setting: A randomized controlled trial. JAMA. 2002;288:2836-45.

101. Unutzer J, Katon WJ, Fan MY, Schoenbaum MC, Lin EHB, Della Penna RD, et al. Long-term cost effects of collaborative care for late-life depression. Am J Manag Care. 2008;14:95-100.

102. van Orden M, Hoffman T, Haffmans J, Spinhoven P, Hoencamp E, van Orden M, et al. Collaborative mental health care versus care as usual in a primary care setting: a randomized controlled trial. Psychiat Serv. 2009;60:74-9.

103. Vera M, Perez-Pedrogo C, Huertas SE, Reyes-Rabanillo ML, Juarbe D, Huertas A, et al. Collaborative care for depressed patients with chronic medical conditions: a randomized trial in Puerto Rico. Psychiat Serv. 2010;61:144-50.

104. Von Korff M, Katon W, Bush T, Lin EH, Simon GE, Saunders K, et al. Treatment costs, cost offset, and cost-effectiveness of collaborative management of depression. Psychosom Med. 1998;60:143-9.

105. Von Korff M, Katon WJ, Lin EH, Ciechanowski P, Peterson D, Ludman EJ, et al. Functional outcomes of multi-condition collaborative care and successful ageing: results of randomised trial. BMJ. 2011;343:d6612.

106. Zwar NA, Bunker JM, Reddel HK, Dennis SM, Middleton S, van Schayck OC, et al. Early intervention for chronic obstructive pulmonary disease by practice nurse and GP teams: a cluster randomized trial. Fam Pract. 2016;33:663-70.

107. Kravetz JD, Walsh RF. Team-based hypertension management to improve blood pressure control. Prim Care Community Health. 2016;7:272-5.

108. Vestjens L, Cramm JM, Birnie E, Nieboer AP. Cost-effectiveness of a proactive, integrated primary care approach for community-dwelling frail older persons. Cost Eff Resour Allocat. 2019;17.

109. Petersen I, Bhana A, Fairall LR, Selohilwe O, Kathree T, Baron EC, et al. Evaluation of a collaborative care model for integrated primary care of common mental disorders comorbid with chronic conditions in South Africa. BMC Psychiat. 2019;19.

110. Seidu S, Bodicoat DH, Davies MJ, Daly H, Stribling B, Farooqi A, et al. Evaluating the impact of an enhanced primary care diabetes service on diabetes outcomes: A before-after study. Prim Care Diabetes. 2017;11:171-7.

111. Sommers LS, Marton KI, Barbaccia JC, Randolph J. Physician, nurse, and social worker collaboration in primary care for chronically ill seniors. Arch Intern Med. 2000;160:1825-33.

112. DePuccio MJ, Hoff TJ. Medical home interventions and quality outcomes for older adults: a systematic review. Qual Manag Healthc. 2013;22:327-40.

113. Gilbody S, Bower P, Fletcher J, Richards D, Sutton AJ. Collaborative care for depression: a cumulative meta-analysis and review of longer-term outcomes. Arch Intern Med. 2006;166:2314-21.

114. Tully PJ, Baumeister H. Collaborative care for comorbid depression and coronary heart disease: a systematic review and meta-analysis of randomised controlled trials. BMJ Open. 2015;5:e009128.

115. Stokes J, Panagioti M, Alam R, Checkland K, Cheraghi-Sohi S, Bower P. Effectiveness of case management for'at risk'patients in primary care: a systematic review and meta-analysis. PloS one. 2015;10.

116. Brady TJ, Murphy L, O'Colmain BJ, Beauchesne D, Daniels B, Greenberg M, et al. Peer reviewed: A meta-analysis of health status, health behaviors, and health care utilization outcomes of the chronic disease self-management program. Prev Chronic Dis. 2013;10.

117. Tan EC, Stewart K, Elliott RA, George J. Pharmacist services provided in general practice clinics: a systematic review and meta-analysis. Res Social Adm Pharm. 2014;10:608-22. 
118. Reynolds R, Dennis S, Hasan I, Slewa J, Chen W, Tian D, et al. A systematic review of chronic disease management interventions in primary care. BMC Fam Pract. 2018;19:11.

119. Milbank Memorial Fund. The Impact of Primary Care Practice Transformation on Cost, Quality, and Utilization. 2017. https://www.pcpcc.org/sites/default/files/resources/pcmh_evidence_report_08-1-17\%20FINAL.pdf Accessed 20 March 2020.

120. Veet CA, Radomski TR, D’Avella C, Hernandez I, Wessel C, Swart EC, et al. Impact of Healthcare Delivery System Type on Clinical, Utilization, and Cost Outcomes of Patient-Centered Medical Homes: a Systematic Review. J Gen Intern Med. 2020:19.

121. Peikes D, Zutshi A, Genevro JL, Parchman ML, Meyers DS. Early evaluations of the medical home: building on a promising start. Am J Manag Care. 2012;18:105.

122. Ekers D, Murphy R, Archer J, Ebenezer C, Kemp D, Gilbody S. Nurse-delivered collaborative care for depression and long-term physical conditions: a systematic review and meta-analysis. J Affect Disord. 2013;149:14-22.

123. Primary Health Care Advisory Group Report. Better outcomes for people with chronic and complex health conditions. 2015. https://www1.health.gov.au/internet/main/publishing.nsf/content/76B2BDC12AE54540CA257F72001102B9/\$File/PrimaryHealth-Care-Advisory-Group_Final-Report.pdf Accessed 12 April 2020.

\section{Figures}

\begin{tabular}{ll}
\hline Participants & Primary care patients aged at least 18 years with one or more chronic disease/s \\
Intervention & AMA recognised PCMH principles (must meet 1 and 2 criteria) \\
& 1) Integrated or MDT care AND \\
2) One or more of the following principles: & i. Coordination of care \\
ii. Data driven quality of care & iii. Long-tem patient-provider relationship \\
iv. Patient empowerment and patient engagement & \\
& Standard GP care \\
Comparison & Patient outcomes (clinical and self-reported surveys) \\
Outcomes & Hospital outcomes (hospital or emergency department visits) \\
& Economic outcomes (direct healthcare costs, incremental costs) \\
Rtudy design & Randomised and non-randomised controlled trials
\end{tabular}

\section{Figure 1}

Summary of PICOS components 


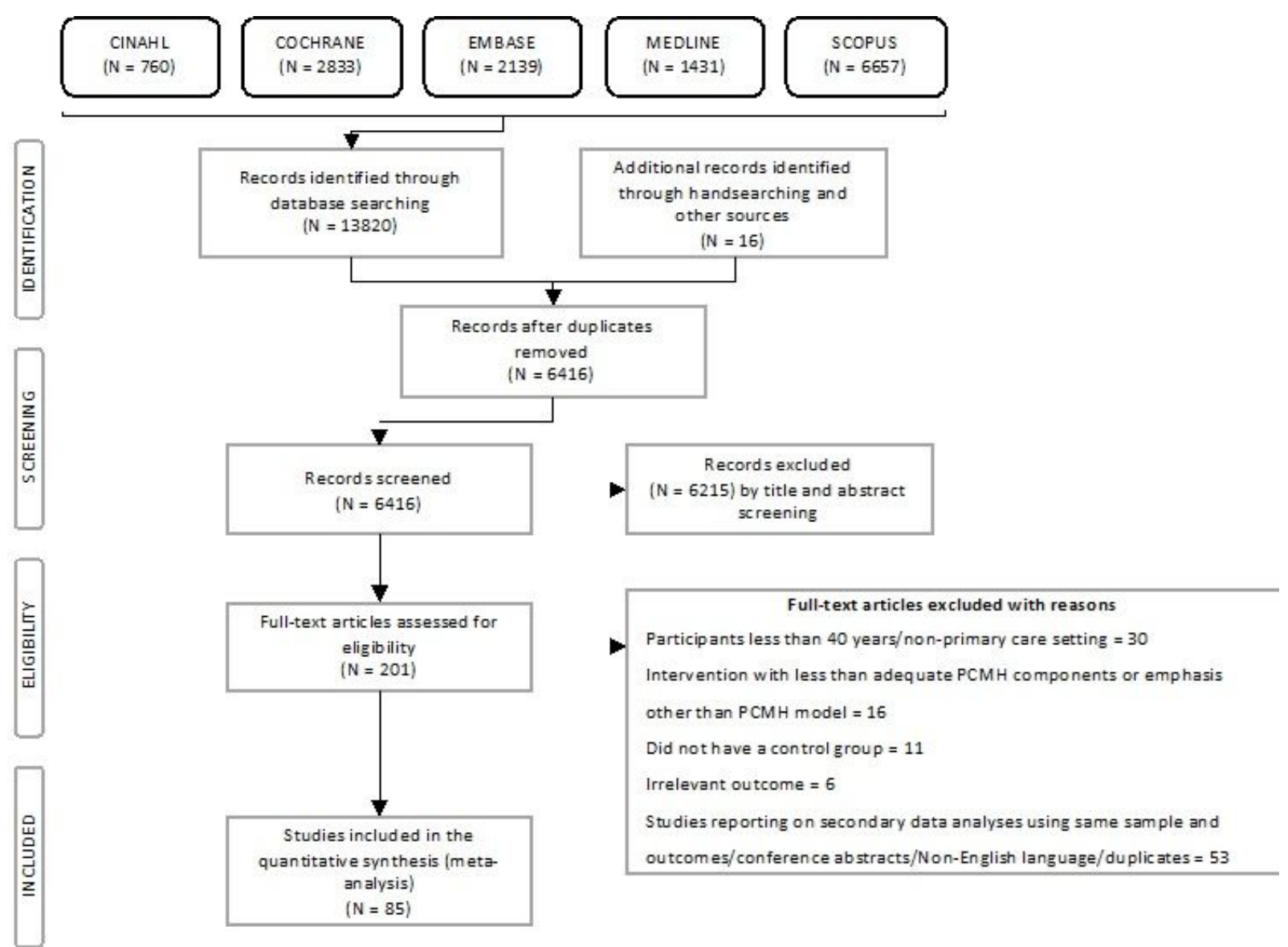

\section{Figure 2}

PRISMA Flowchart 


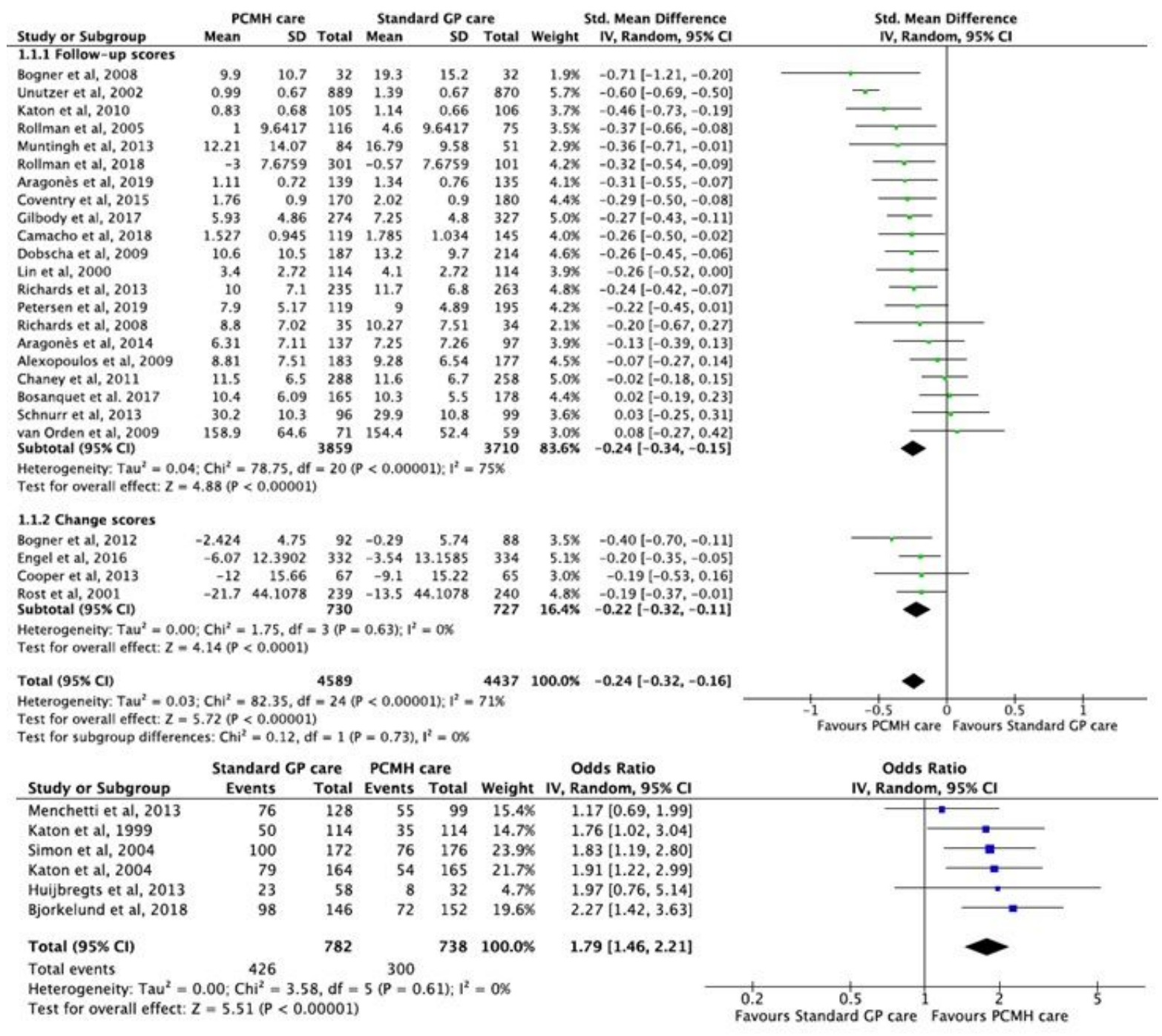

\section{Figure 3}

Forest plots of depression outcomes between the PCMH care and Standard GP care. 


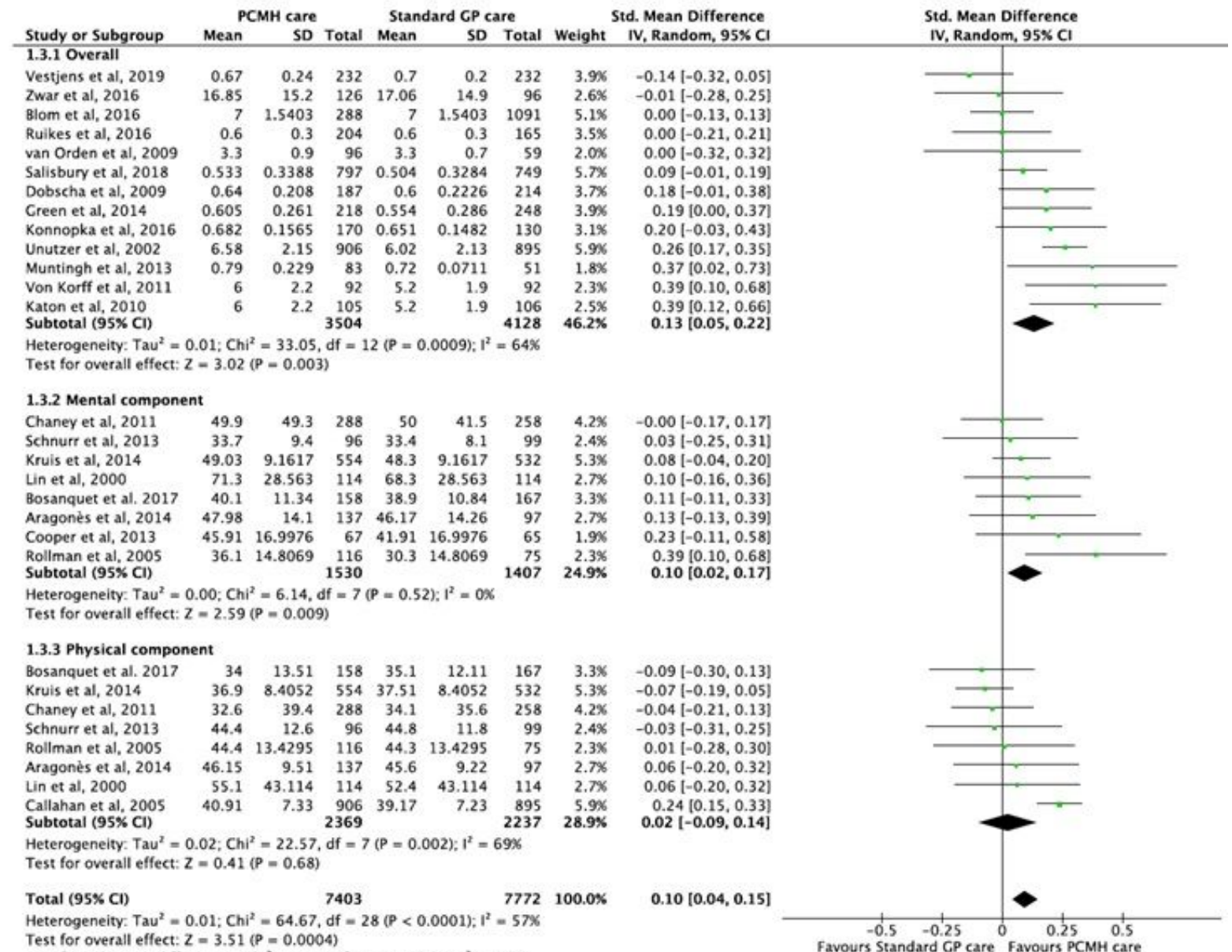

\section{Figure 4}

Forest plots of Quality of life (QoL) outcomes between the PCMH care and Standard GP care. 


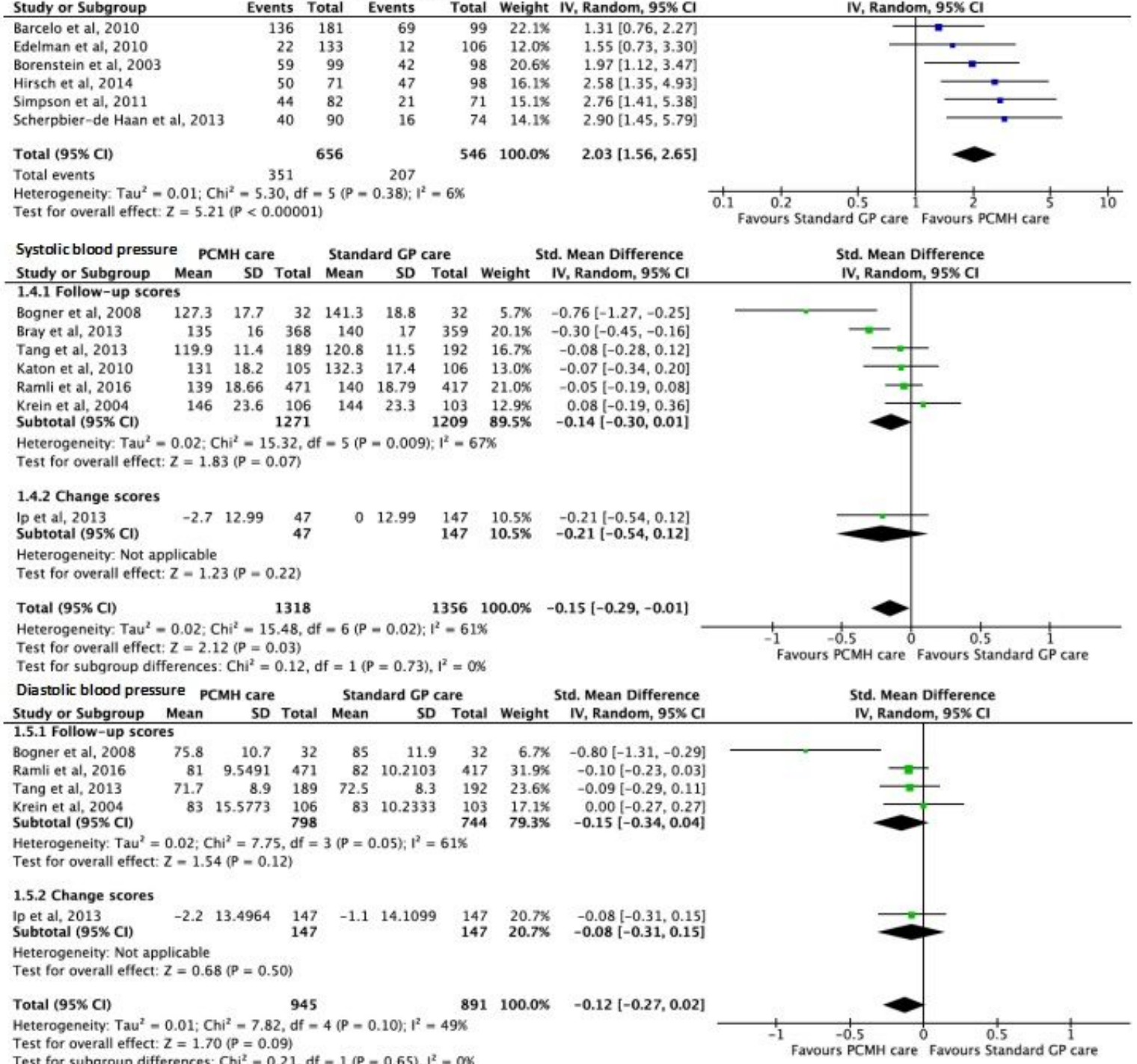

Test for subgroup differences: $\mathrm{Chi}^{2}=0.21, \mathrm{df}=1(\mathrm{P}=0.65), \mathrm{I}^{2}=0.6$

\section{Figure 5}

Forest plots of blood pressure outcomes between the PCMH care and Standard GP care. 


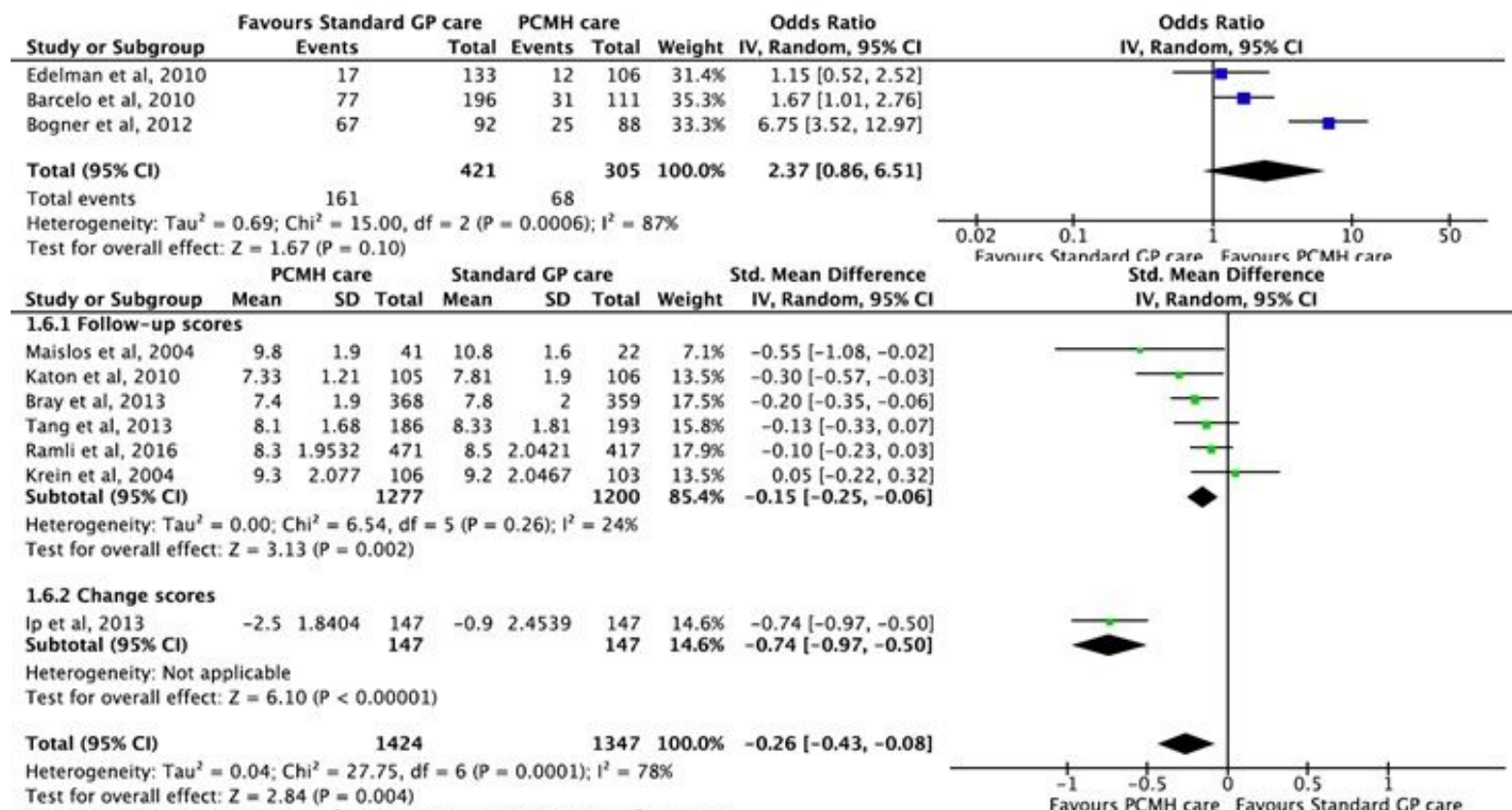

Test for overall effect: $Z=2.84(P=0.004)$

Test for subgroup differences: $\mathrm{Chi}^{2}=19.96, \mathrm{df}=1(\mathrm{P}<0.00001), \mathrm{I}^{2}=95.0 \%$

Favours PCMH care Favours Standard CP care

\section{Figure 6}

Forest plots of HbA1c outcomes between the PCMH care and Standard GP care.

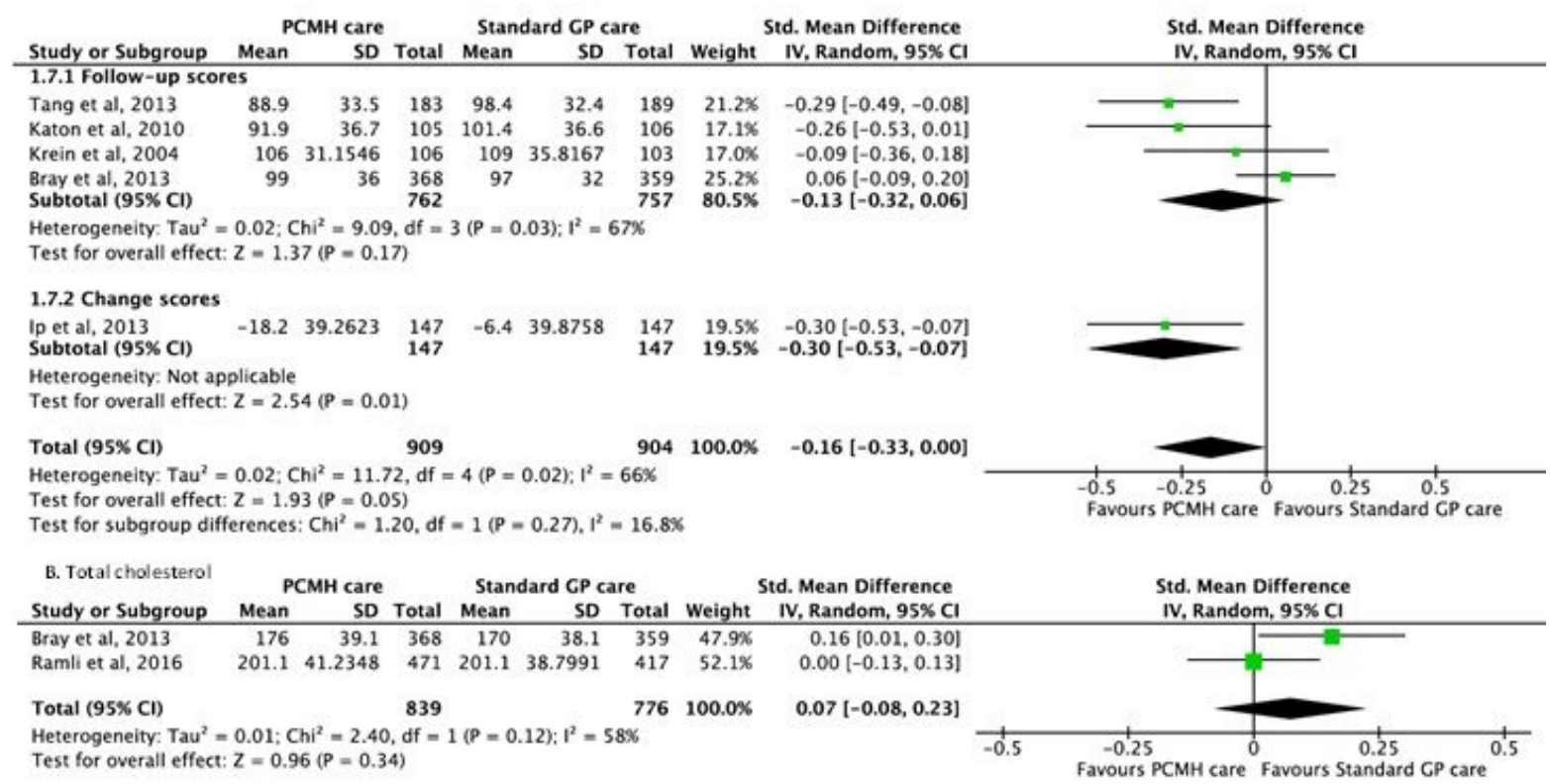

\section{Figure 7}

Forest plots of cholesterol outcomes between the PCMH care and Standard GP care.

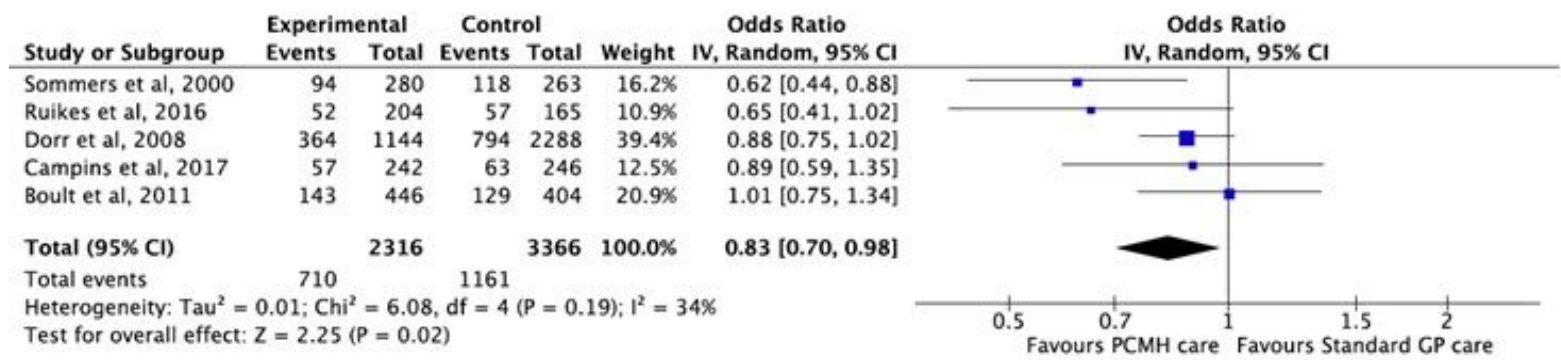


Figure 8

Forest plot for hospital admissions between PMCH care and Standard GP care.

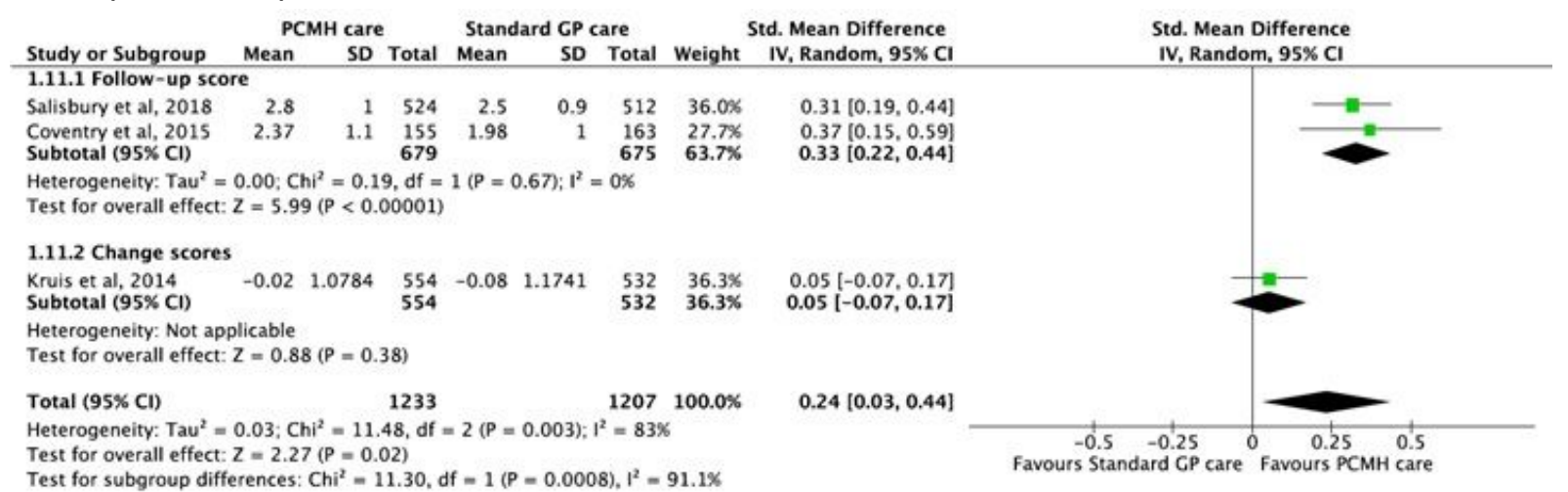

\section{Figure 9}

. Forest plots of self-management outcomes (PACIC scores) between the PCMH care and Standard GP care.

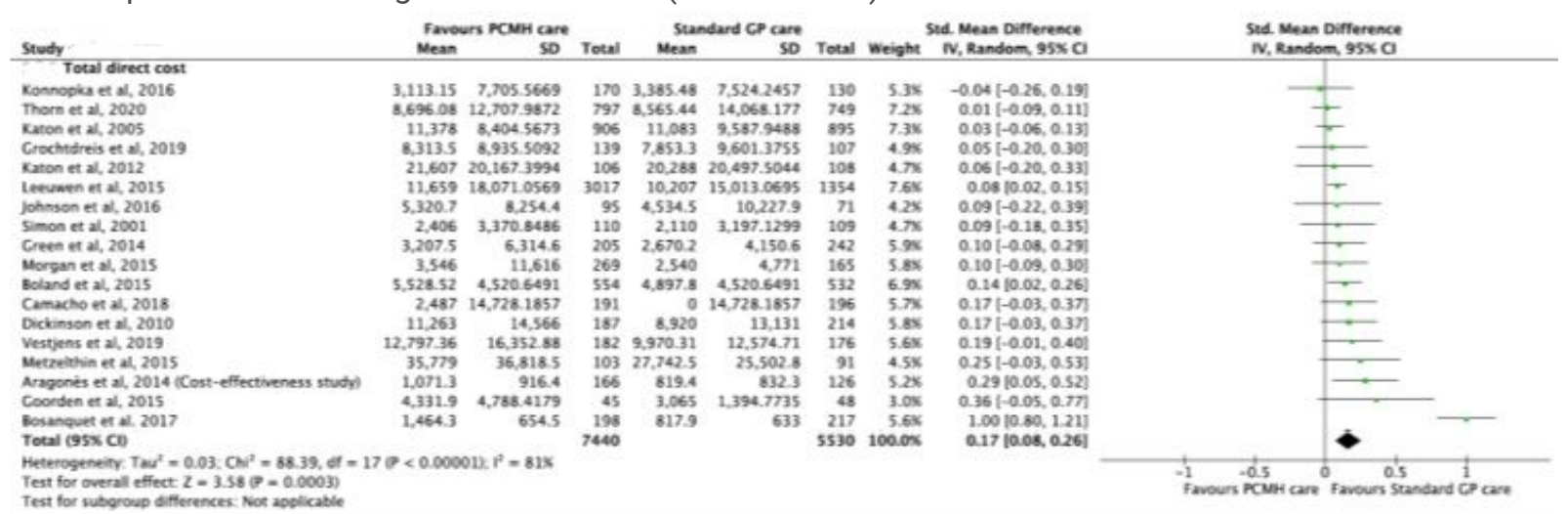

\section{Figure 10}

Forest plots of incremental cost of intervention between the PCMH care and Standard GP care. 

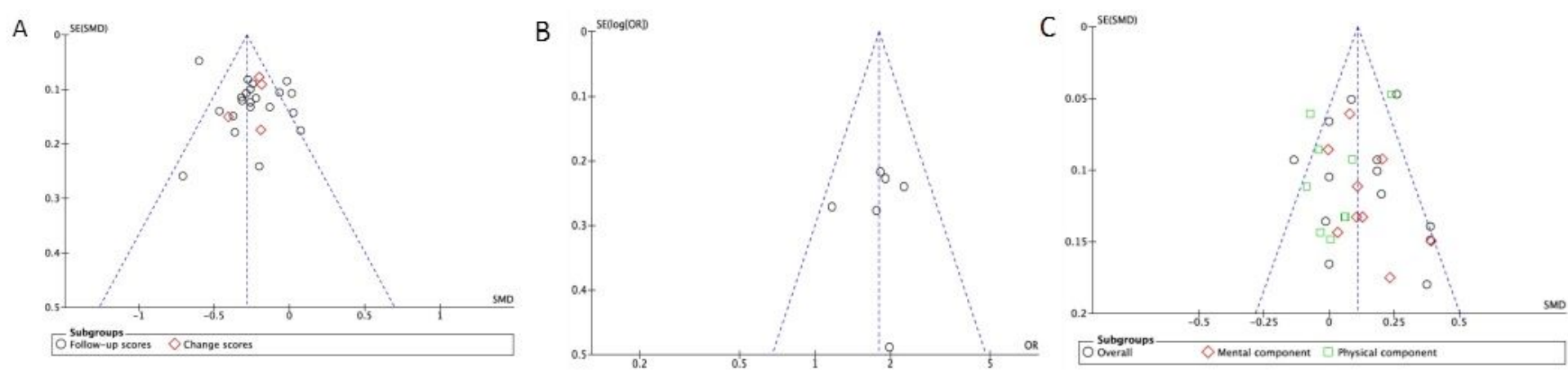

D
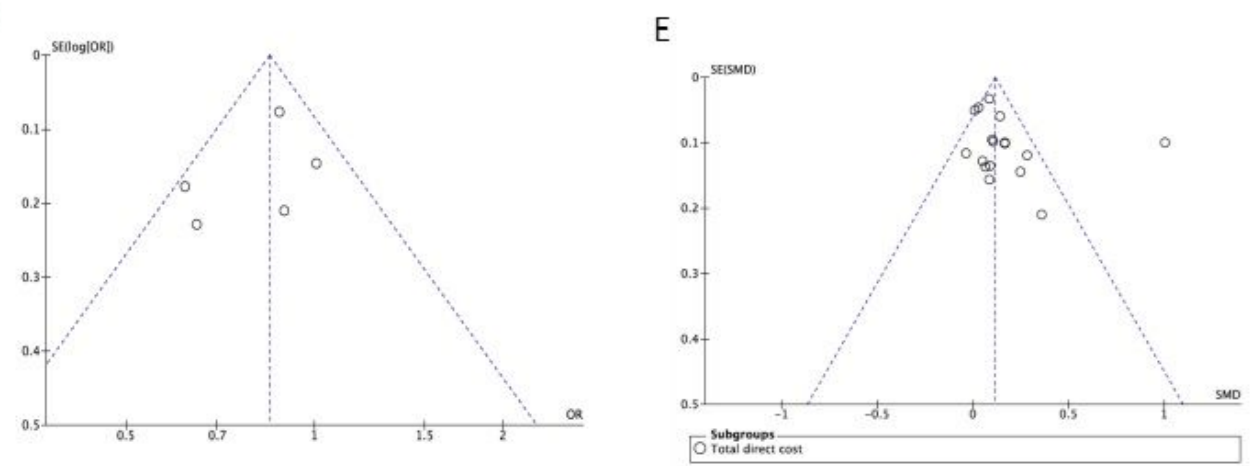

\section{Figure 11}

Funnel plots assessing asymmetry of depression, QoL, hospital admissions, and cost outcomes between the PCMH care and Standard GP care. A - Depression (SMD); B - Depression (OR); C - Quality of Life (SMD); D - Hospital admissions (OR); E Direct costs
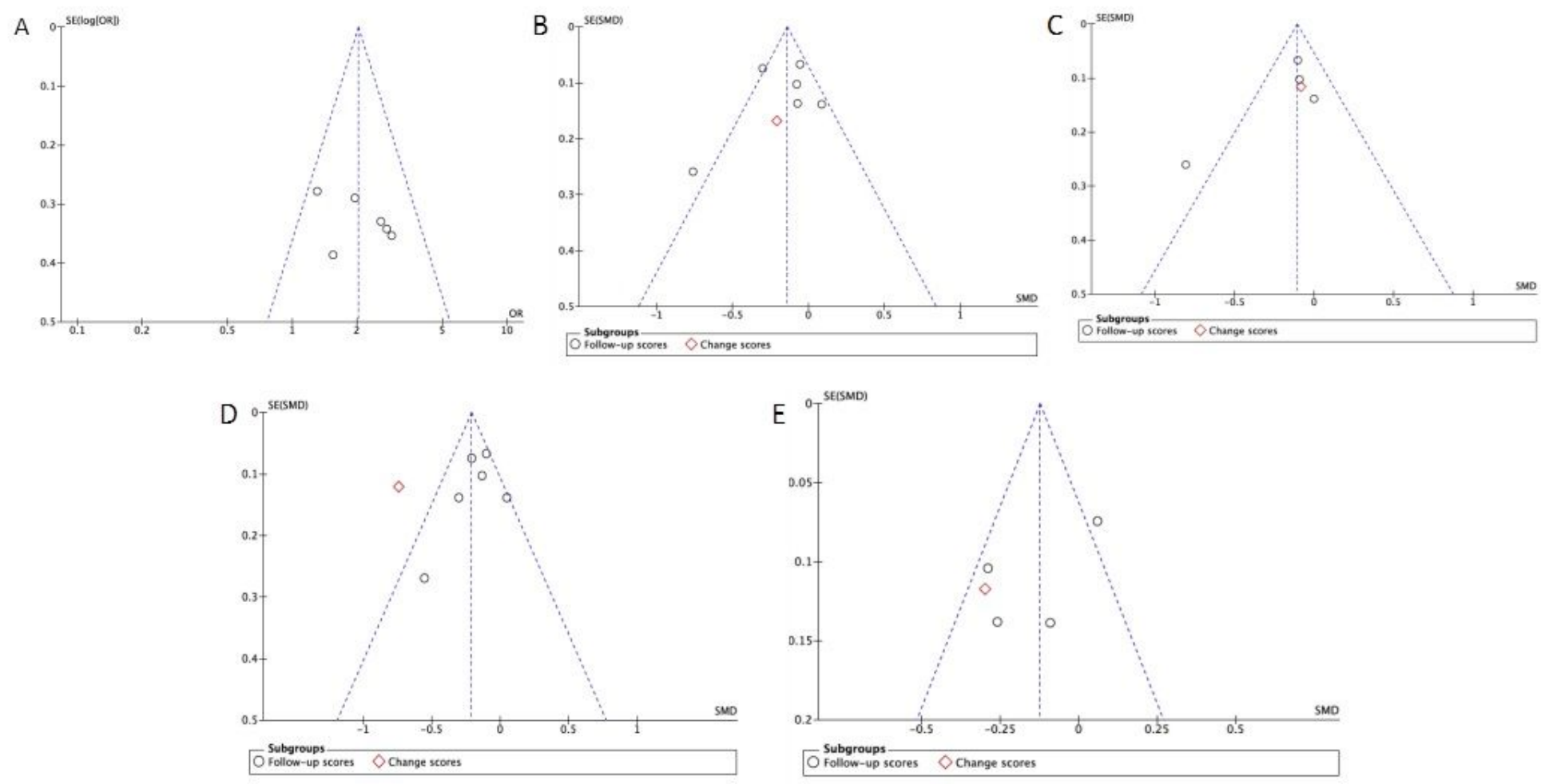

\section{Figure 12}

Funnel plots assessing asymmetry of clinical outcomes between the PCMH care and Standard GP care. A - Blood pressure (SMD); B - Systolic blood pressure (OR); C - Diastolic blood pressure (SMD); D - HbA1C (OR); E - LDL cholesterol 


\section{Supplementary Files}

This is a list of supplementary files associated with this preprint. Click to download.

- PRISMA2009checklist.doc

- Appendix8ROBINSI.docx

- Appendix57Qualityassessments.docx

- Appendix34Characteristicsofincludedstudies.docx

- Appendix2Reasonsforexclusion.docx

- Appendix1Searchterms.docx 